\title{
Overview of host miRNA properties and their association with epigenetics, long non-coding RNAs, and Xeno-infectious factors
}

Samaneh Heydarzadeh ${ }^{1}$, Maryam Ranjbar ${ }^{2}$, Farokh Karimi ${ }^{3}$, Farhad Seif ${ }^{4,5}$ and Mohammad Reza Alivand ${ }^{1,2^{*}}$

\begin{abstract}
MicroRNA-derived structures play impressive roles in various biological processes. So dysregulation of miRNAs can lead to different human diseases. Recent studies have extended our comprehension of the control of miRNA function and features. Here, we overview some remarkable miRNA properties that have potential implications for the miRNA functions, including different variants of a miRNA called isomiRs, miRNA arm selection/arm switching, and the effect of these factors on miRNA target selection. Besides, we review some aspects of miRNA interactions such as the interaction between epigenetics and miRNA (different miRNAs and their related processing enzymes are epigenetically regulated by multiple DNA methylation enzymes. moreover, DNA methylation could be controlled by diverse mechanisms related to miRNAs), direct and indirect crosstalk between miRNA and Inc (Long Non-Coding) RNAs as a further approach to conduct intercellular regulation called "competing endogenous RNA" (ceRNA) that is involved in the pathogenesis of different diseases, and the interaction of miRNA activities and some Xeno-infectious (virus/bacteria/parasite) factors, which result in modulation of the pathogenesis of infections. This review provides some related studies to a better understanding of miRNA involvement mechanisms and overcoming the complexity of related diseases that may be applicable and useful to prognostic, diagnostic, therapeutic purposes and personalized medicine in the future.
\end{abstract}

Keywords: MicroRNA, IsomiR, Arm selection, DNA methylation, LncRNA, Xeno-infection

\section{Introduction}

MicroRNAs (miRNAs) with 18-25 nucleotides are highly conserved non-coding (NC) RNAs that can be found in C. elegans to homo sapience and can play vital roles in the regulation of gene expression [1,2]. The locations of human miRNAs are almost in intergenic and intragenic or intronic regions of the genome [3]. The maturation of miRNAs is done by Drosha and Dicer as RNase III enzyme, from the nucleus to the cytoplasm of cells [4]. Then, these miRNAs are associated with Argonaute (Ago)

\footnotetext{
*Correspondence: mohammadreza_alivand@yahoo.com; alivandm@tbzmed. ac.ir

${ }^{1}$ Department of Medical Genetics, Faculty of Medicine, Tabriz University of Medical Sciences, Tabriz, Iran

Full list of author information is available at the end of the article
}

protein to produce the effector RNA-induced silencing complex (RISC) and contribute to the RISC complex to scan the related targets [5]. The unique and important role of miRNAs refers to post-transcriptional regulation by endonucleotide cleavage or inhibition of mRNA translation through the formation of miRNA- induced silencing complex (miRISC) on target sites in the $3^{\prime}$ untranslated region (UTR) of mRNAs [6]. Each miRNA can target multi mRNAs. Moreover, each transcript can be targeted by various miRNAs simultaneously. Although the role of miRNAs in ongoing biological processes, including apoptosis, metabolism, differentiation $[7,8]$, signal transduction [9], and other normal function of the cell has been demonstrated by numerous studies, their dysregulation leads to disruption of mRNA expression profiling in various disease processes $[10,11]$, organ 
transplant rejection [12], rheumatoid arthritis [13], cardiovascular diseases [14], diabetes [15], etc., particularly cancer development [16] and viral infections [17]. It makes miRNAs potential targets for cancer therapies, prognostic biomarkers, or diagnostic signs in diverse diseases.

MiRNAs have several distinct features compared to other functional RNA species. In this regard, diverse variants of a miRNA's so-called isomiRs can affect the miRNA target selection. They are complex property of miRNAs that play functional roles in some diseases such as lipid homeostasis [18], Alzheimer's disease [19], and different cancers [20]. Also, the next-generation sequencing (NGS) studies have shown that isomiRs circulate in the bloodstream with high stability similar to mature miRNA. Thus they might act as novel biomarkers along with miRNAs for malignancies [21]. Arm selection and arm switching are the other remarkable properties of miRNAs. which impact on miRNA function and their imbalance has been considered by many scientists as a significant issue in finding the cause of diseases such as cancer [22, 23]. It is important that although two arms of pre-miRNA (5p and 3p) are relatively complementary [24], each arm includes various related isomiRs that the functional arm involves target detection based on their affinity to RISC complex [25].

Regulation of miRNA expression through molecular epigenetic mechanisms is another important subject in the field of miRNAs and pathogenesis. DNA methylation of miRNA locus and miRNA processing genes leads to the regulation of their expression. On the other hand, multiple miRNAs can target and control the methylationrelated enzymes and factors to affect epigenetics event. Aberrant expression of miRNA mediated by epigenetics and aberrant activity of DNA methylation enzymes mediated by miRNA are important in the pathogeneses of diseases [26]. It can provide a strategy for early diagnosis and treatment of cancer in vitro and in vivo [27]. Additionally, the interaction between miRNA and lnc-RNAs as competing endogenous RNA control miRNA-mRNA binding and have therapeutic importance in cancer [28].

Valuable studies confirmed that there is a significant correlation between miRNAs and some infectious factors and agents; therefore, it can affect the progress or regress of these diseases [29-31]. There are applicable issues mentioned above to plan future direction in controlling diseases. In this review, we first provide a brief overview of some miRNA properties from variation in their sequence (isomiR) to regulation of miRNA arm selection/switching and the effect of some factors on these two features. We then collected some evidence about the relationship between miRNA and epigenetics, long noncoding RNAs, and Xeno-infectious factors. Altogether, the regulation of miRNA function mediated by these factors is an important issue; therefore, it can provide new insight into the etiology of diseases and their treatment.

\section{miRNA properties}

The miRNA sequences and their maturation had been conserved from primary to higher eukaryotes. The primary transcript of miRNAs ( $\leq 100 \mathrm{bp}$ ) is processed using a two-step mechanism with two RNase III enzymes in the nucleus and cytoplasm. Firstly, Drosha in collaboration with DiGeorge syndrome critical region 8 (DGCR8) accessory protein as a microprocessor complex binds to double-stranded miRNA and cleaves it to the generate pre-miRNA ( $\sim 70 \mathrm{bp})$ [32]. After transmission of pre-miRNA to the cytoplasm using the Exportin-5 and Ran-GTP complex, the subsequential processing of miRNA is done by Dicer as the second RNase III and generates the matured double-strand miRNA (20-23 bp). RISC-loading complex includes double-stranded RNA, Dicer, the trans-activating response RNA-binding protein (TRBP), and Argonaut 2 that is essential for activation of RISC complex to follow related mRNAs using suitable single-stranded miRNA as guide RNA [33]. The discovery of the frequency of miRNAs in various multicellular species raised intriguing questions, including what these molecules may do in the cell. The key response is to find their mRNA targets. In other words, highly conserved miRNAs have extremely conserved targets. In the miRNA, there are several interaction sites with target mRNAs to direct post-transcriptional repression. Many sites that match the miRNA seed region (nucleotides $2-7$ ), particularly those in $3^{\prime}$ UTRs, are preferentially conserved. Four types of these sites are 6 mer site, which perfectly matches the 6 -nt miRNA seed, 7 mer-m8 site that involves the seed match complete by a Watson-Crick match to miRNA nucleotide 8,7 mer-A1 site, which contains the seed match supplemented by an A across from miRNA nucleotide 1 , and 8 mer site, which includes the seed match supplemented by both $\mathrm{m} 8$ and the A [34]. Furthermore, experiments using artificial sites show that targeting can also occur in $5^{\prime}$ UTRs, especially in open reading frames (ORFs) [35].

In silico study of miRNAs, like the other members of the genome, requires databases. Recently, five criteria databases have been developed. At first, miRBase was developed, which provided nomenclature for newly discovered miRNA genes, thereby making available the annotation and sequences of all published miRNAs from various organisms to researchers [36]. MirGeneDB 2.0 is a manually created metazoan miRNA gene database that has a more complementary nomenclature system than MiRBase. Also, it contains previously overlooked miRNAs and seven organisms that are not currently listed in 
miRBase. However, it contains fewer entries than miRBase [37]. MiRCarta is another miRNA database, which provides collection of validated novel human miRNAs and enhances the information provided by miRBase. In fact, miRCarta illustrate a more inclusive companion to manually created resources such as MirGeneDB [38]. Also, miRTarBase (http://miRTarBase.mbc.nctu. edu.tw/), miRDB (http://mirdb.org), miR-EdiTar (http:// microrna.osumc.edu/mireditar), TransmiR v2.0 (http:// www.cuilab.cn/transmir), miRandb (http://mirandb.ir), HMDD v3.0 (http://www.cuilab.cn/hmdd), and Immune$\mathrm{miR}$ (http://www.biominingbu.org/immunemir/) are the other important databases in the field of miRNA.

\section{miRNA isomiRs}

Mature miRNAs consist of various variants that are diverse in length and/or sequence so-called isomiRs [39]. For the first time, isomiRs of miRNAs were determined by RNA-Seq approaches and it has been observed that any miRNA has different isomiRs with multiple copy numbers. IsomiRs are classified into three main types, including $3^{\prime}, 5^{\prime}$ and polymorphic isomiRs with different nucleotide sequences compared with canonical miRNA (Fig. 1) in which $3^{\prime}$ isomiRs are most common in animals and plants [40-42] (Fig. 1a). Both $5^{\prime}$ and $3^{\prime}$ isomiRs are divided into homogenous (template) and or heterogeneous (non-template) variants. Polymorphic isomiRs are known as non-template sequences. The difference between these variants is attributed to their sequence that is match or non-match with the genome (parent gene) [41].

There are some mechanisms to generate these various isomiRs. Processing heterogeneity as the main process is involved in the generation of $5^{\prime}$ and or $3^{\prime}$ template isomiRs, provided by Drosha and or Dicer imprecise cleavage in the $5^{\prime}$ and or $3^{\prime}$ ends. A further mechanism is nucleotide trimming mediated by some exoribonucleases or some nucleotidyltransferases that are less common for the generation of template isomiRs in animals, bacteria, humans, and others. The mentioned mechanisms are common in $3^{\prime}$ end rather than $5^{\prime}$. Additionally, post-transcriptional enzymatic processes that made non-template isomiRs are comprised of (1) nucleotide addition by ribonucleotidyl transferase mainly uridyltransferase and adenyltransferase [43, 44], (2) nucleotide removal, which these two changes often occur in $3^{\prime}$ isomiRs, (3) adenosine (A) to inosine (I) RNA editing by the double-stranded RNA-specific adenosine deaminase (ADR) enzyme that is the most prevalent RNA-editing enzyme in isomiRs. RNA editing may occur in the seed

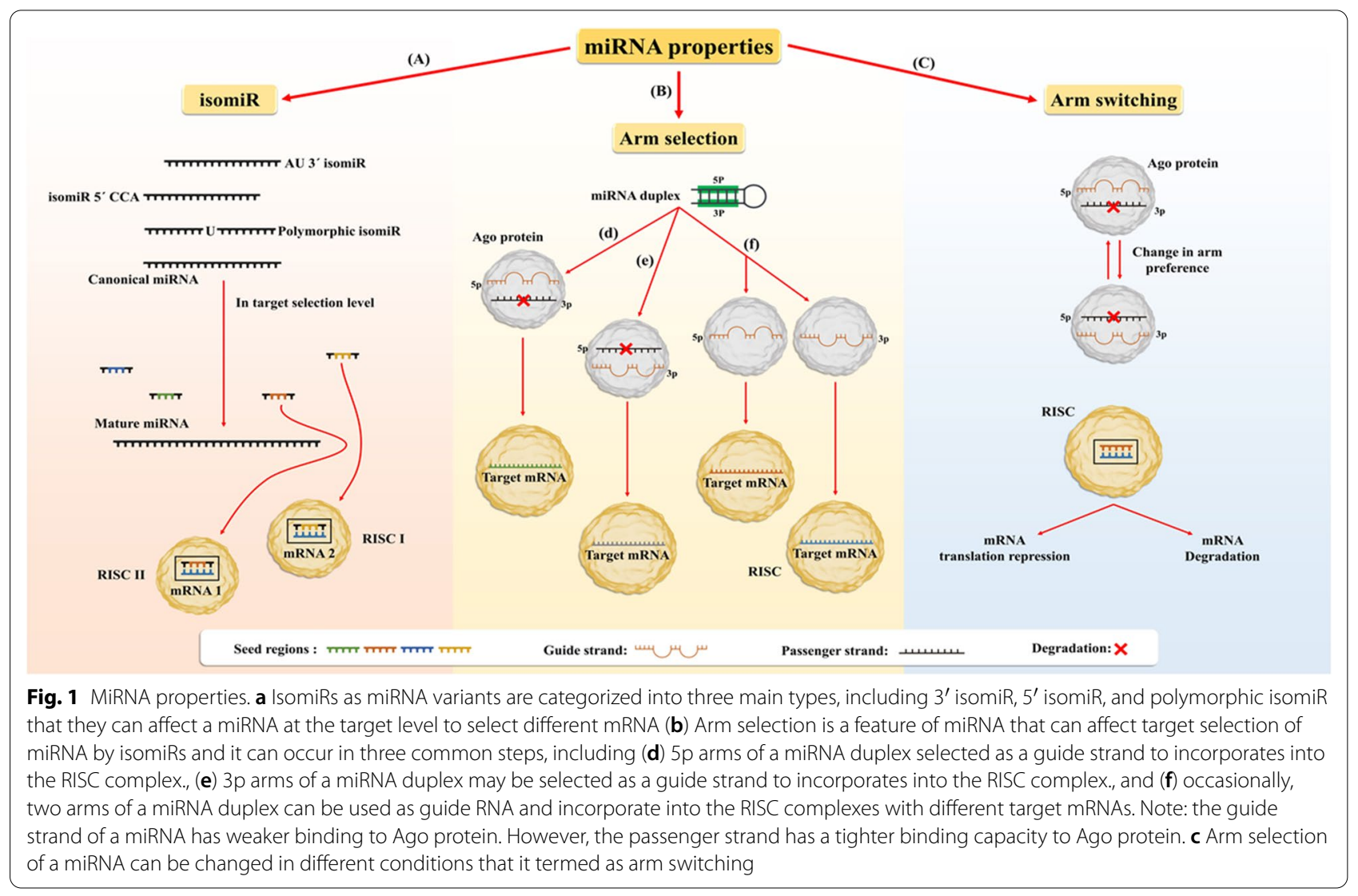


region of $5^{\prime}$ end, in the $3^{\prime}$ end nucleotides or internal nucleotides and generate $5^{\prime}, 3^{\prime}$ and polymorphic isomiRs, respectively. This mechanism is the major process in the generation of polymorphic isomiRs [41, 45]. According to different pieces of evidence, all of the generated modifications could affect different functions of a miRNA such as a target selection, efficiency to target in RISC complex, diversity, stability, and half-life of miRNA [46-51].

Based on isomiR profiling, the isomiR variation of a miRNA is related to cells and tissue types [52]. Also, they are associated with the individual's gender, population origin, and race that all of them dependent on a dynamic and regulated maturation process that originated from the response to various biological inductions $[53,54]$. More recent studies demonstrated that specially derived isomiRs could be applied as more effective prognostic and diagnostic biomarkers in various cancers and related subtypes, thus they can differentiate healthy and non-healthy individuals. For example, isomiR-140-3p is confirmed in the prevention of triple-negative subtype of breast cancer and there are ongoing studies regarding the prediction of further disease [55]. Also, different isomiRs of miR-222 could play distinct roles, as a result, it may be used as a biomarker in breast cancer cells and other tumors [57]. These observations further support the fact that diverse isomiRs from the same mature miRNA can target practically non-overlapping collection of transcripts. Accordingly, so far, some reliable approaches have developed with high sensitivity to the detection of isomiRs that could facilitate this detection. One of the novel applications is Quagmire with a flexible searching algorithm that analyzes heterogeneous isomiRs from next-generation sequencing data and identifies different isomiRs [58]. Recently, Comprehensive Approach to Sequence-oriented isomiR annotation (CASMIR) database that facilitates precise interpretation of isomiR features in small RNA sequencing data among species and miRDeep2, which is a favorite algorithm of miRNA analysis to accredit isomiR interpretation by CASMIR, are two ways of analysis of isomiRs [59].

Several tools have been developed to analyze miRNAs and their respective isomiRs that these are different in their abundance cut-offs, isomiR annotation methods, ways to handle cross-mapping events, or alignment strategies. A number of bioinformatics tools only can analyze and detect isomiRs without their functional annotation, including CPSS, IsomiRex, MODOMICS, MiRGator v3.0, and SeqBuster. In the meantime, SeqBuster is a reliable, more flexible and highly versatile web-based toolkit due to overcoming storage capacity limitations through providing a stand-alone version that can permit the annotation against any custom database [60-64]. Up to now, SeqBuster, miRspring, isomiRex, YM500v2, YM500,
RNASEQR, and miRGator v3.0 as isomiR databases have been used to diagnose cancer [65]. IsomiR-SEA as a novel tool based on RNA-Seq analysis can accurately detect miRNAs/isomiRs expression level profiling and evaluate conserved miRNA-mRNA interaction sites [66]. SRNAbench is the other high-throughput analytic tool for profiling of miRNAs' isomiRs in one or simultaneously multiple species [67]. MiRge 2.0 is a tool, which widely analyzes miRNA sequencing data and exclusively captures the potential miRNAs by using both composition of isomiRs and miRNA hairpin sequence structure [68]. The software PRocessing Of Short Transcripts (Prost), helps quantify mature miRNAs that accounts for posttranscriptional processing such as nucleotide editing and identifies mirror-miRNAs [69]. Additionally, there are some other platforms or software to study miRNA/ isomiR such as miR-isomiRExp, miRWalk2.0, DIANA miRPath v.2.0, mirBridge, GeneSet2miRNA, miRror2.0, and C2Analyzer [70].

Recently, an optimized miRNA analysis project called miRNA Transcriptomic Open Project (miRTOP) has been designed. The purpose of miRTOP is to develop the downstream isomiR analysis tools that are compatible with available quantification and detection tools. Also, it solves the lack of consensus between related tools and allows any tool to convert results into mirGFF3 format as a standardized output format for miRNAs/isomiR analyzing [71].

\section{Arm selection and arm switching of miRNAs}

Before scanning and selecting the target by miRNA, there are two steps that add complexity and specificity to its roles. One of them is "arm selection" as a highly controlled process. In this regard, each miRNA is formed from 3 and $5 p$ arms of precursor miRNA (pre-miRNA). Although the derived $3 p$ and $5 p$ arms of miRNA are mostly complementary and derived from the same transcript, they result in different isomiR expression profiles and patterns under different situations; for example, each $5 p$ and $3 p$ arms could participate in various RISC complexes as guide strands or one of the involved arms is degraded as a passenger RNA in the RISC complex (Fig. 1b) [25, 72-74]. Therefore, some factors can be involved in guide strand selection of RISC, including lower thermodynamic stability at the $5^{\prime}$ end and its weaker binding of $5^{\prime}$ end of a strand to the AGO2 protein to direct specific RISC toward the target gene. It seems AGO2 protein plays a major role in this process $[75,76]$. Additionally, any post-transcriptional modifications on the $5^{\prime}$ - or $3^{\prime}$-end of each strand of miR duplex can considerably affect arm selection [41, 77-79]. Also, the frequency of isomiRs can be important in involving the selected arm. For example, a study showed that affluence 
of miR-140-3p isomiRs, compared with miR-140-5p, leads to the formation of a novel seed region in $3 p$ arm, which is more functional than the original consensus one to detect targets in human cartilage cells [80].

Furthermore, some other factors can determine guide RNA selection, such as U/C base at the $5^{\prime}$-end of a strand and an excess of purines/pyrimidines in guide RNA [81] that are directly or indirectly derived from different expression levels of protein activator of dsRNA-dependent protein kinase (PACT), DICER, TRBP and $5^{\prime}-3^{\prime}$ exoribonuclease (Xrn)-1/2 in various cells and tissue types $[82,83]$ as well as the abundance of target's copy numbers may contribute to arm preference [84]. Another aspect of miRNA is related to miRNA's biological ability to switch strand preference called "arm switching" (Fig. 1c). The loaded arms of RISC are related to the frequency of them. Arm switching events are different at various differentiation states, various cells and tissue types (such as a variety of species and gender) possibly due to alternative Dicer cleavage or Drosha processing [85-87]. Thus, arm switching is a mechanism that plays vital roles in the evolution of miRNA gene functions under different conditions in mRNA targeting [25, 88, 89].

Accordingly, some reports showed that both arms of a miRNA can conduct distinct targets and play different roles in cancer. For instance, both miR-193a-3p and miR193a-5p expression decrease in gastric cancer cells and their ectopic expression show that miR-193a-5p inhibited these cells' growth, but only miR-193a-3p remarkably repressed cell invasion via directly targeting ETS1 and CCND1 expression [90]. Furthermore, miR-324-3p and $-5 p$ were significantly overexpressed in lung cancer cells, so their ectopic expressions have different effects on lung cancer cell line and the overexpression of miR324-3p only enhance cell proliferation but did not alter the invasion of these cells, while miR-324-5p significantly promoted both cell invasion and proliferation[92]. Altogether, the arm selection and/or arm switching have key functions in the regulation of isomiRome and miRNAome profiles and lead to changes in isomiR/miRNA expression profiles to evolutionary and/or functional pressures. Also, these results suggest that miRNAs arm switching and or arm selection could be the other essential mechanism of miRNA variation and applicable biomarkers in various diseases such as cancers.

\section{Crosslinking between DNA methylation and miRNAs}

DNAmethylation is a dynamic and reversible event that its status depends on the regulation of such involved enzymes through further factors. Accordingly, such documents demonstrated that miRNAs could target and control the mentioned enzymes. Moreover, various miRNAs located in $\mathrm{CpG}$ islands and shores could be controlled epigenetically. Although DNA methylation could impact the expression of miRNAs via their promoter region, it can regulate the expression of miRNA processing-related enzymes [57, 92-94]. Therefore, DNA methylation affects both miRNAs and processing related enzymes. Some miRNAs such as miR-29 family (29a, 29b, and 29c) could target directly and indirectly DNA methylationrelated enzymes such as TETs and DNMTs, and histonemodifying enzymes; for example, histone deacetylase 4 (HDAC4) and histone methyltransferase SET domain bifurcated 1 (SETDB1) are impaired in various cancer e.g., lung cancer, breast cancer, hepatocellular cancer, etc. [95-102]. Additionally, a study indicated that as miR-29 could control the other miRNAs expression such as miR34c and miR-449a by targeting DNMT3a and 3b [103]. Other studies established that miR-29b modulated the global DNA methylation through targeting DNMT3A and DNMT1, leading to decreased transcription factor specificity protein 1 (SP1) and increased p21 expression in chronic lymphocytic leukemia (CLL) cells [104]. $\mathrm{MeCP} 2$ is one of the other target genes for miRNA-29a as an epigenetic mediator. Overexpression of MiR-29a leads to a decrease in the Bromo domain-containing protein 4 (BRD4) signaling and zinc finger protein SNAI1 expression and downregulated methyl-CpG-binding protein 2 (MeCP2) in mouse hepatic stellate cells (HSCs) [105]. It seems the miR-29 family plays a vital role in the modulation of epigenetic phenomenon compared with other associated miRNAs.

One research declared that co-transfection and overexpression of miR-339 and miR-766 lead to inhibition of DNMT3b upregulation in colon cancer. Subsequently, it results in reactivating the expression of such tumor suppressor genes SFRP1, SFRP2, DKK2 and WIF1 in these cells [106]. MiR-221 is another miRNA involved in DNMT3b targeting, which can elevate the cancer stem cell properties such as Oct3/4 and Nanog through downregulation of DNMT3b in breast cancer cell lines [107]. According to a study, both mir-148b and mir-152 can reactivate some tumor suppressor genes such as SPARC and BNIP3 by targeting DNMT-1, thereby resulting in modification of methylation status of the mentioned tumor suppressor genes and reducing tumorigenic properties in pancreatic cancer cell lines [108].

To the best of our knowledge, there are two studies on miRNA-140 and methylation regulation. Accordingly, miR-140, as a tumor suppressor, controls NF-kB activity by direct targeting Dnmt1 and conducting hypomethylation and overexpression of metallothionein genes to indirectly enhance NF- $\mathrm{kB}$ activity in a liver cell line [109]. The second one shows that miR-140-5p can regulate $\mathrm{CD}_{4}^{+} \mathrm{T}$ cell differentiation through demethylation of GATA3 and hypermethylation of STAT1. In addition, it 
is involved in the tricarboxylic acid (TCA) cycle by the regulation of methylation status of mediated transcription factors that may be associated with TET2 activities. Therefore, mir- 140 probably performs its epigenetic roles by controlling both Dnmt1 and TET2 [110]. Based on in vitro and in vivo experiments, there are downregulated and upregulated miRNAs such as miR-212, miR-373, miR-638, miR-106a, miR-221/222, miR-19a/b, miR-132, miR-7b, miR-130a, miR-22, miR-483-5p and miR-218 that may control the expression level of Methyl-CpGbinding protein MECP2 as a reader of DNA methylation [111-115117-124]. Furthermore, Methyl-CpG-binding domains (MBDs) i.e., MBD1 and MBD2 could be regulated through miR-195-5p, miR-224 in various diseases. Therefore, DNA methylation could be modulated by miRNAs involved in targeting of MBD proteins [125, 126] (Table 1).

According to different studies, some miRNAs are regulated by their methylated locus or promoter region. For example, miR-200c and miR-141 play important roles in the Epithelial-Mesenchymal Transition (EMT) event of solid cancers that both of them are regulated epigenetically [127-131]. In prostate cancer, the promoter region of miR-200c and miR-141 are hypermethylated, leading to downregulation of their expression [132]]. This association between miR-141 and miR-200c is confirmed in gastric and breast cancers, respectively [133, 134]. Another miRNA involved in gastric cancer invasion is miR-7-5p that its silencing by methylation of its promoter leads to an increase in its target genes, namely
Smo and Hes1 [135]. Furthermore, the promoter methylation of miR-7 is a significant and early-stage biomarker in cisplatin-resistance and clinical management of ovarian and lung cancer cells [136] (Table 2).

Although miRNAs could be controlled epigenetically and vice versa, the expression of miRNA processing enzymes, including DROSHA, DGCR8, EXPORTIN5, Dicer, and TRBP, can be affected by DNA methylation and its related factors directly or indirectly [137] (Fig. 2). According to studies, methylation of some $\mathrm{CpG}$ sites in the gene body of Drosha has a significant correlation with the stimulation of transcriptional elongation in cancer cells $[138,139]$. The further study reported that MeCP2 binds to DGCR8 and suppresses the DGCR8/ Drosha complex directly in the brain [140]. In contrast, Drosha can also affect and maintain DNA methylation by mediating DNMT1 activity [141]. As a result, there is a bilateral association between Drosha complex and DNA methylation. Exportin-5 (XPO5), as a master protein, exports pre-miRNAs from nuclear to the cytoplasm. The related study showed that XPO5 promoter methylation status controls its expression level in breast cancer patients [142].

The association of Dicer, as another processing enzyme in DNA methylation, was demonstrated through some studies. Accordingly, in Cholangiocarcinoma (CCA) was declared that the overexpression and translocation of Dicer to the nucleus and formation complex with heterochromatin protein $1 \alpha(\mathrm{HP} 1 \alpha)$ leads to hypermethylation of SFRP1 promoter and suppression of its transcription

Table 1 Effect of the related miRNAs on DNA methylation

\begin{tabular}{|c|c|c|c|c|}
\hline miRNA & miRNA expression & Outcome & Disease & Refs. \\
\hline miR-29 family & Down-expressed & $\begin{array}{l}\text { Decrease targeting DNMT1, 3A, 3B and } \\
\text { TET1 }\end{array}$ & $\begin{array}{l}\text { Multiple myeloma, lung cancer, Burkitt } \\
\text { lymphoma, breast cancer, nasopharyn- } \\
\text { geal carcinoma }\end{array}$ & $\begin{array}{l}{[79-81,95} \\
97-100,102]\end{array}$ \\
\hline miR-339 and miR-766 & Down-expressed & Decrease targeting DNMT3B gene & Colorectal cancer & $\begin{array}{l}{[11,108,107} \\
113-115 \\
122,124 \\
183]\end{array}$ \\
\hline miR-221 & Over-expressed & $\begin{array}{l}\text { Increase directly targeting DNMT3b 3’UTR } \\
\text { region }\end{array}$ & Breast cancer & {$[184]$} \\
\hline miR-148b and miR-152 & Down-expressed & decrease targeting DNMT-1 mRNA & Pancreatic cancer & {$[185]$} \\
\hline miR-140 & Down-expressed & Decrease directly targeting DNMT-1 & Liver cancer & {$[90]$} \\
\hline miR-140-5p & & $\begin{array}{l}\text { Decrease DNA methylation of STAT1 and } \\
\text { Tbx genes CpG island }\end{array}$ & Autoimmune encephalomyelitis & {$[186]$} \\
\hline miR-212 & $\begin{array}{l}\text { Down-expressed } \\
\text { Down-expressed }\end{array}$ & Increase MeCP2 protein level & Gastric cancer & {$[187]$} \\
\hline miR-373 & Down-expressed & Increase MBD2 expression & Hilar cholangiocarcinoma & {$[188]$} \\
\hline miR-638 & Down-expressed & Increase MeCP2 mRNA level & Gastric cancer & {$[189]$} \\
\hline miR-221/222 & Down-expressed & Increase MBD2 expression & Cervical cancer & {$[190]$} \\
\hline miR-19a/b & Down-expressed & Increase MeCP2 expression & Gastric cancer & {$[191]$} \\
\hline miR-132 & Over-expressed & Decrease MeCP2 expression & Chronic Cerebral Hypo perfusion & [192] \\
\hline
\end{tabular}


Table 2 Effect of DNA methylation on miRNAs

\begin{tabular}{|c|c|c|c|c|}
\hline miRNA & Expression & Mechanism & Disease & Refs. \\
\hline miR-874 & Down expressed & Hyper methylation of the promoter region & Breast cancer & {$[194]$} \\
\hline miR-129-2 and miR-9-1 & Down expressed & DNA methylation of the miRNA promoter CpG island & Renal cell carcinoma & {$[75]$} \\
\hline miR- 10b-3p & Over expressed & Promoter hypo methylation & Esophageal squamous cell carcinoma & {$[195]$} \\
\hline miR-141 & Down expressed & Hyper DNA methylation & Gastric cancer & {$[108]$} \\
\hline $\operatorname{miR}-145$ & Over expressed & Demethylation of the promoter region & Breast cancer & {$[50]$} \\
\hline miR-200c and miR-141 & Over expressed & Hypomethylation of the promoter region & Colorectal Cancer & {$[109]$} \\
\hline miR-200c/141 & Down expressed & $\begin{array}{l}\text { Hyper methylation of } \mathrm{CpG} \text { island located in the promoter } \\
\text { region }\end{array}$ & Invasive breast cancer & {$[114]$} \\
\hline miR-370 & Down expressed & $\begin{array}{l}\text { Hyper methylation of two CpG islands located in the } \\
\text { upstream of miR genomic locus }\end{array}$ & Osteosarcoma & {$[196]$} \\
\hline miR-941 and miR-1247 & Down expressed & Hyper methylation of the CpG island in miRs loci & Gastric cancer & {$[197]$} \\
\hline $\operatorname{miR}-7-5 p$ & Down expressed & Hyper methylation of the promoter site & Gastric cancer & {$[116]$} \\
\hline miR-21 and miR-146b & Over expressed & Hypo methylation of miRs promoter region & Papillary thyroid carcinoma & {$[198]$} \\
\hline $\operatorname{miR} 124-2$ & Over expressed & Hypo methylation of CpG site in miR gene & Breast Cancer & {$[199]$} \\
\hline miR-183 & Down expressed & Hyper methylation of the miR promoter & Hepatocellular carcinoma & [200] \\
\hline
\end{tabular}

through recruiting Dnmts [143]. Another study showed that Dicer indirectly could control methylation of Xist promoter in Embryonic Stem (ES) cells through Dnmt3a regulation [144]. There is a relationship between Dicer and methylation status by controlling of DNMTs in various human cancer cells [145]. It seems that Dicer is indispensable to the maintenance of methylation status throughout the genome.

Despite the association of DNA methylation with the expression of various miRNAs, RNA methylation of primiRNAs can modify their expression. RNA methylation is a reversible and dynamic event that is mostly performed in $\mathrm{m} 6 \mathrm{~A}$ position by specific-related enzymes such as ALKBH5 and METTL3 [146, 147]. RNA methylation of various positions in pri-miRNAs could be impacted by the interaction of processing enzymes such as Dicer [148]. Additionally, the expression of METTL3 could be controlled by DNA methylation. Therefore, RNA methylation is regulated by DNA methylation [149]. Although N6-methyladenosine (m6A) modification is more common, 7-methylguanosine (m7G) as a further RNA modification has been reported in miRNA regulation like hypermethylation of let-7 pri-miRNA by METTL1 [150].

\section{The interaction between miRNAs and Incs}

In addition, the specificity, feature, and function of a miRNA can be affected by the structural variants of the miRNA itself or by epigenetics, which play a significant role in the normal function of the cell or diseases; these can be affected by other RNAs, including lncRNAs.

According to significant in vitro and in vivo studies, lnc RNAs as long non-coding RNAs (>200 bp) involve in many cellular processes and various diseases, which could interact with other non-coding RNAs such as miRNAs to modulate their roles [151]. LncRNAs originate from intragenic and intergenic regions that can activate or repress gene expression at multiple levels through diverse mechanisms, and their interaction with miRNAs is a complex mechanism to regulate target genes. Consequently, the effects of lncRNA-miRNA on the regulation network have attracted extensive attention in medical research [152-154]. This interplay has different aspects. In some cases, miRNAs interact with the miRNA-binding site of lncRNA like their target mRNAs (Fig. 3a), thereby triggering to disturb lncRNAs by miRNAs [155, 156]. In other cases, IncRNAs can compete with miRNAs to bind to the related mRNA (Fig. 3b) or act as miRNA sponges/decoys (Fig. 3c) in some pathway of the cells socalled competing endogenous RNA (CeRNA). Obviously, lncRNA competes with mRNAs for sequestering or binding to miRNAs through matching the miRNA response elements (MREs) [157]. Although there are reports that show the CeRNA abundances alteration from individual genes can modulate the activity of miRNAs, some studies demonstrated the modulation of miRNA target abundance unlikely have significant effects on the gene expression and metabolism through CeRNA [158]. Multiple studies show that lncRNA-miRNA collaboration is the most prevalent collaboration in cancer. In this regard, numerous studies have been performed. For example, lnc-ABCA12-3 is a novel oncogene in esophageal squamous cell carcinoma (ESCC) competes with endogenous miR-200b-3p to regulate the expression of fibronectin 1 (FN1) in metastatic stages of the tumor [159]. Furthermore, the overexpressed IncRNA HAGLROS in hepatocellular carcinoma cell and tissue leads to inhibition of 


\section{miRNA and methylation}

Effect of methylation on miRNA

1) HiRnA related gene Promoter region

2) +ำi⿱⺈ Promoter region

Dicer

Gene promoter

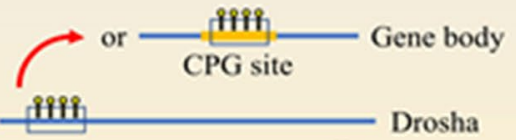

Gene promoter

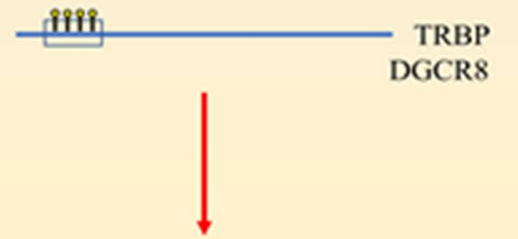

No expression

or

Down expression of $\mathrm{miR}$

DNA methylation: 부요

Other factors:

Translation repression:

Dmnt:

Dmnt1:

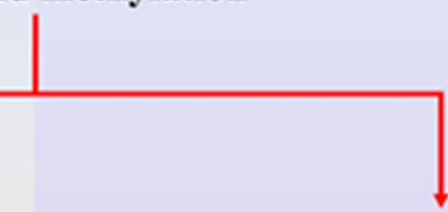

\section{Effect of miRNA}

on methylation

1)

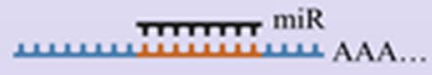

DNA

methylation related enzymes

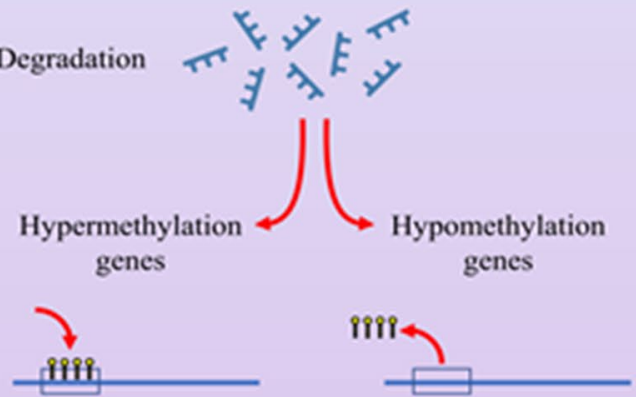

2)

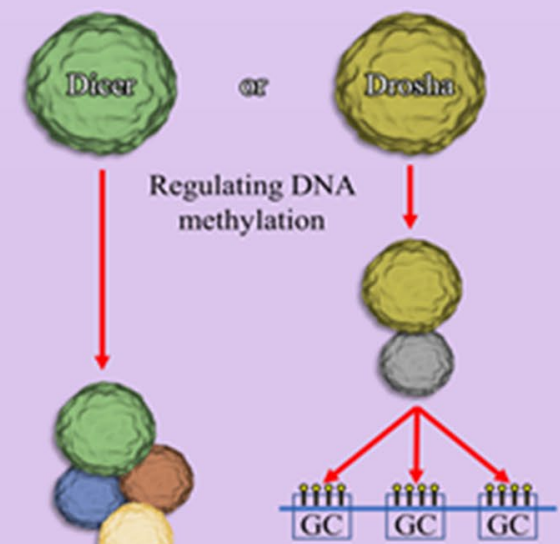

Genomic methylation

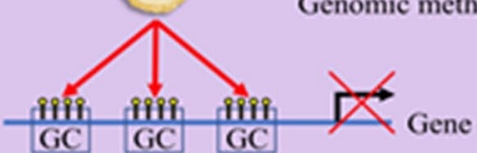

Gen methylation

Fig. 2 MiRNA and methylation: miRNA and DNA methylation have interaction with each other in two ways, including the effects of miRNA on methylation and vice versa. DNA methylation can affect 1) miRNA-related gene or 2) promoter region of miRNA processing enzymes and cofactors such as TRBP and DGCR8 and also can affect CPG sites of Drosha gene body. Mutually, a miRNA can affect DNA methylation in two ways, including 1) it can target genes of DNA methylation-related enzymes such as DNMTs, TETs, MECP2, and MBDs, and leads to hyper-or hypo-methylation of different genes. 2) Also, miRNA processing-related enzymes can directly or indirectly affect DNA methylation through recruiting DNMTs to CpG sites in the genome or at gene levels 
Interaction of miRNA and LncRNA

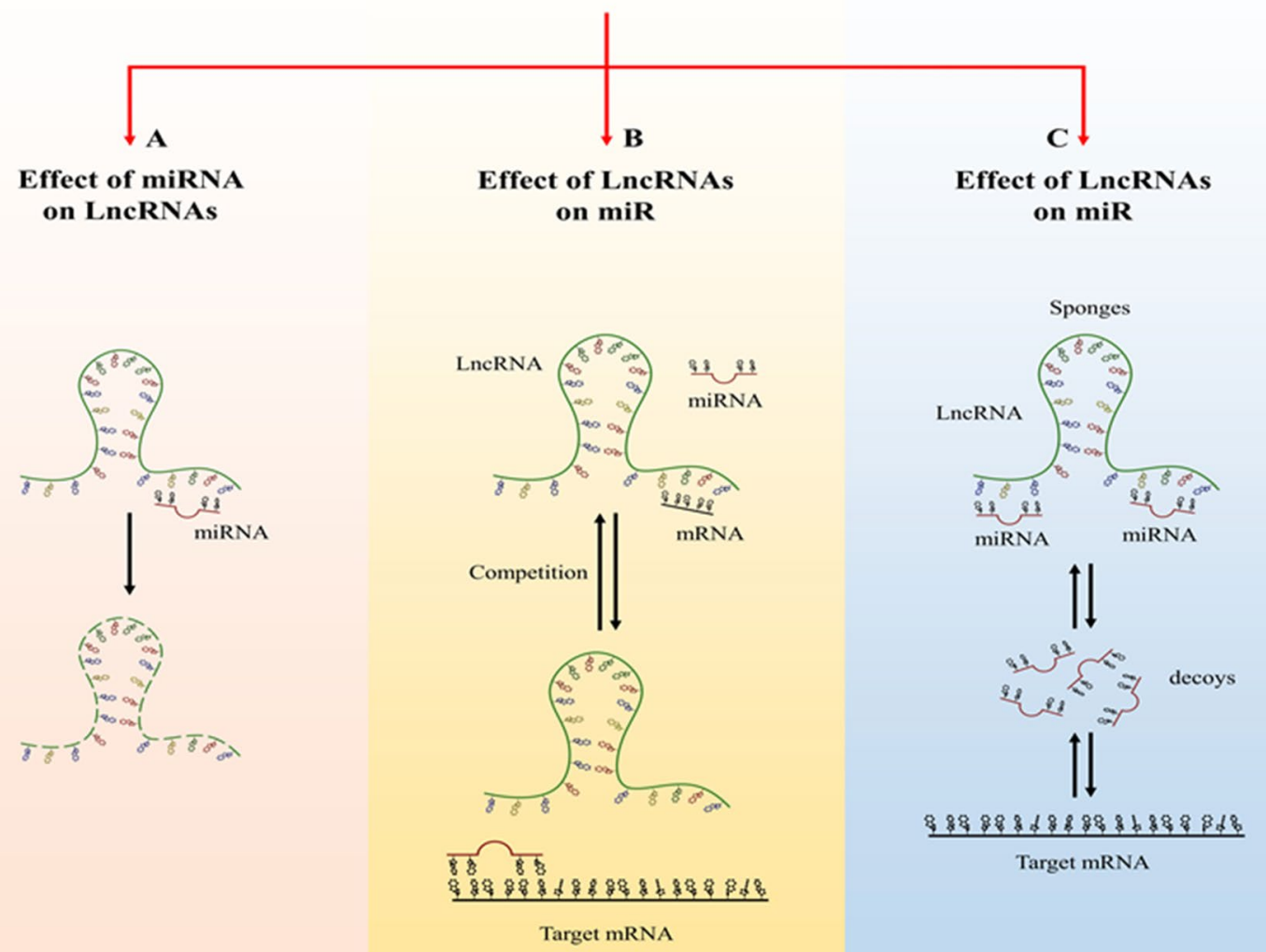

Fig. 3 Interaction between miRNA and IncRNA. There are three states of collaboration among miRNAs and IncRNAs: a miRNA can bind to its binding site of IncRNA and weak IncRNA stability. $\mathbf{b}$ LncRNA and miRNA can compete with each other to binding to target mRNA. c Also, IncRNA can affect the binding of miRNA to target mRNA through sponging the miRNA. However, sometimes miRNA can decoy from IncRNA and bind to related $\mathrm{mRNA}$

miR-5095 and elevated expression of its target, ATG12 [160]. Another study reported that lncRNA H19 is overexpressed and increases NOX4 expression through miR148b-3p suppression [161]. This association was observed between different lncRNAs such as MIR205HG, NEAT1, SNHG20, SNHG1, SNHG12, GIHCG, TUSC-7, ATB, MEG3, GAS5, PCF, AL445665.1-4, lnc-p21, LINC00339, TINCR and related miRNAs, including miR-590-3p, miR-129-5p, miR-495, miR-577, miR-16, miRNA-1281, miR-146, miR-141-3p, miR-147, miR-21, miR-344a-5p, miR-146b-5p, miR-625, miR-497-5p, miR-214-5p in normal and cancerous cells, respectively (Table 3) [56, 91, 160, 162-173].

Furthermore, a study demonstrated that lncRNA can inhibit miRNA expression by affecting its promoter region (Fig. 3c); for example, LncRNA-p23154 controls
miR-378a-3p expression through this way in oral squamous cell carcinoma [174]. In addition to the studies mentioned above, lncRNA can also affect a miRNA in two ways. For instance, overexpression of LncRNAmiR503HG as a decreasing lncRNA in ovarian cancer (OC) cells may decrease the expression of miR-31-5p via sponging of miR-31-5p and increasing miR-31-5p gene's methylation [175]. Some miRNAs are involved in inhibition of IncRNA activities that may have a reciprocal interaction between lncRNAs and miRNAs; for example, IncRNA XIST and miR-132-3p repress each other in CRC cells [176]. Also, this association was shown in Lnc-OC1/miR-34a/34c of OC and MALAT1/miR-101 of Glioblastoma (GBM) cells, respectively $[177,178]$. The mutual interaction between LNC-ZEB1-AS1 and miR101 was demonstrated in CRC tissues and cells [179]. 
Table 3 Interaction between IncRNA and miRNA

\begin{tabular}{|c|c|c|c|c|}
\hline LncRNA & miRNA & ceRNA & Disease & Refs. \\
\hline$A B C A 12-3$ & miR-200b-3p & - & Esophageal squamous cell carcinoma & \\
\hline HAGLROS & miR-5095 & Sponging & Hepatocellular carcinoma & $\begin{array}{c}{[56,146} \\
159 \\
162- \\
168]\end{array}$ \\
\hline MIR205HG & miR-590-3p & Sponging & Head and Neck Squamous Cell Carcinoma & [49] \\
\hline NEAT1 & miR-129-5p & Sponging & Papillary thyroid cancer & [148] \\
\hline SNHG2O & miR-495 & Sponging & Breast cancer & {$[140]$} \\
\hline SNHG1 & miR-577 & Sponging & Osteosarcoma & [142] \\
\hline SNHG12 & miR-16 & Sponging & Colorectal cancer & [144] \\
\hline GIHCG & miRNA- 1281 & - & Gastric cancer & [143] \\
\hline TUSC-7 & miR-146 & Sponging & Lung adenocarcinoma & [141] \\
\hline ATB & miR-141-3p & Sponging & Breast cancer & [149] \\
\hline MEG3 & miR-147 & - & Chronic myeloid leukemia & $\begin{array}{c}{[72,91} \\
149 \\
169- \\
173]\end{array}$ \\
\hline GAS5 & miR-21 & Sponging & Ovarian cancer & [152] \\
\hline PCF & miR-344a-5p & - & pulmonary fibrosis & [4] \\
\hline AL445665.1-4 & miR-146b-5p & - & Multiple uterine leiomyoma & {$[153]$} \\
\hline Inc-p21 & miR-625 & - & Neuronal injury & {$[150]$} \\
\hline LINC00339 & miR-497-5p & Sponging & Pancreatic cancer & [201] \\
\hline TINCR & miR-214-5p & Sponging & Hepatocellular carcinoma & {$[151]$} \\
\hline
\end{tabular}

The growing various in silico and experimental studies help demonstrate the RNA-RNA interactions that functionally impact the related gene regulation derived from detailed primary and secondary structure predictions and their validations. Therefore, synthetic RNAs can have therapeutic applications in the mentioned targets.

\section{The miRNA and transcript association between xeno-infections and host}

Accordingly, another complexity of miRNAs is their effects on xeno-infection's RNAs that lead to moderate severity and weakness of associated diseases. Moreover, some miRNAs of parasites could probably target the expression of host-related mRNAs because of the conservative sequence of miRNAs from primary to higher organisms. Therefore, the up- and down-regulation of special miRNAs can control the virulence genes in various infections. Also, miRNAs and their related isomiRs can affect or be affected by various populations and immune system activation against infections, especially viral infections that lead to crucial modifications in the miRNA/ isomiR repertoire, which indicates miRNAs' role and variances of immunity in different hosts alongside the infection [180].

There are several interaction levels between the host's miRNAs and RNAs of different viruses. Regarding various virus infections, some host's miRNAs can target critical virus-related mRNAs or part of the virus genome. For example, miR-296-5p is significantly upregulated in enterovirus 71 (EV71)-infected human cells and inhibits replication of the virus by targeting the two regions of the viral genome [181]. Moreover, miR-125b-5p can negatively regulate hepatitis $\mathrm{C}$ virus $(\mathrm{HCV})$ infection via targeting Human antigen $\mathrm{R}(\mathrm{HuR})$ as an affirmative regulator of HCV replication in both liver carcinoma cells and serum of HCV-infected patients [182]. Also, miR-28-3p inhibits the transmission of human $\mathrm{T}$ cell leukemia virus, type 1 (HTLV-1) to T cells by blocking the reverse transcription step of the virus genome [183].

Further studies showed that the number of host miRNAs can influence virus infection by targeting some host factors. For instance, miR-939 decreases the frequency of Hepatitis B virus (HBV) RNAs by targeting host factors like Jmjd3 that it is an enhancer for transcription efficiency of HBV [184]. Also, miR-10a-5p directly targets the signal recognition particle 14 (SRP14) that leads to a decrease in the extracellular viral RNA expression of PRRSV and its multiplication [185]. In a study, ggamiR-29a-3p and gga-miR-19b-3p repressed Newcastle Disease Virus (NDV) multiplication, while the gga-miR199-5p and gga-miR-451 stimulated this infection.In this regard, it was demonstrated that gga-miR451 performs its role via targeting host factor of tyrosine 3 monooxygenase/tryptophan5-monooxygenase activation protein 
zeta (YWHAZ) [186]. Additionally, hsa-miR-199a has an antiviral effect through the downregulation of a Golgilocalized GTPase-activating protein for Cdc42 called ARHGAP21 in the Herpes Simplex Virus-1(HSV-1) infection [187]. In addition to the above, some miRNAs such as miR-122 play a dual function in the proliferation of Human Papillomavirus (HPV) and Hepatitis C virus (HCV) in infected cell lines $[188,189]$.

Regarding other studies about the effects of viral factors on the host's miRNA expression, some virusrelated intergenic non-coding RNAsequences of the virus genome can decline the host miRNAs during pathogenesis by affecting the maturation of miRNAs [190]. In a study, the NS3 protein of HCV can upregulate miR-27a; meanwhile, downregulate miR-150 and miR-335 expression in LX-2 liver cells, thereby enhancing the pathogenesis of related diseases [191]. Furthermore, hepatitis $\mathrm{B}$ virus $\mathrm{X}$ protein $(\mathrm{HBx})$ represses the expression of miR-30e by increasing its promoter methylation that leads to developing hepatocarcinogenesis and liver fibrosis [192]. Also, dengue virus (DENV) and Borna disease virus 1 (BoDV-1) induce hsa-miR-146a overexpression to control the IRAK1/ TRAF6/NF- $K B$ signaling pathway in host cells to facilitate viral replication [193]. Other mechanisms of the virus to escape from the host immune system in influenza A virus (IAV) is the mutation of the NS1 gene as a major regulator of pathogenicity that helps to virus proliferation by disrupting the antiviral response of hsa-miR-1307-3p [195]. The appearance of new coronavirus disease 2019 (COVID-19) that has also been termed severe acute respiratory syndrome coronavirus 2 (SARS-CoV-2) with rapid spreading, severe symptoms, which affects the lung, heart, kidney cells, etc. [196-198] by targeting Angiotensin-converting enzyme 2 (ACE2) receptors and the whole world faced a pandemic. Given that the interaction between miRNA and virus materials has been established in various diseases, some miRNAs, which can target capsid protein-coding genes of the virus or ACE2, may be used as a therapeutic solution to inhibit or attenuate COVID-19.

According to the association between miRNAs and microbes involved in the pathogenesis of the disease, there is some gut microbiota such as Proteobacteria, Bacteroidetes, and Firmicutes that correlate with colorectal cancer (CRC) by inducing some oncogenic miRNAs such as miR-503, miR-182and mir-17 92 cluster [199]. In this regard, Zhou et al. reported that tumor suppressor miR-203, which targets CASK oncogene, can be downregulated by Helicobacter pylori infection and promoted the proliferation and invasion of gastric cancer [200]. Recent findings of the association between host miRNAs and parasites have shown that they can play reciprocal roles in this regard to modulate pathogenesis. For example, mmu-miR-101b-3p is increased in the infection of a nematode (larvae), Angiostrongylus cantonensis, and could reduce the pathological effect of the parasite in the host by targetting extracellular superoxide dismutase 3 (Acsod3) in vitro and in vivo [201]. Furthermore, miR$146 \mathrm{a}$ and miR-155 as a biomarker are upregulated in Toxoplasmosis that modulates inflammatory factors in hosts [202]. Also, Toxoplasma gondii infection can alter the expression levels of miR-17 $\sim 92$ and miR-106b $\sim 25$ clusters that contribute to enhancing the related diseases [203].

On the other hand, some miRNAs of parasites can also impact the host cells. For instance, the extracellular vesicle (EVs) miRNAs cargo like miR-125b and bantam miRNAs derived from Schistosoma japonicum leads to an increase in TNF- $\alpha$ production and macrophage proliferation in host cells by targeting and regulating Fam $212 \mathrm{~b}$, Pros1, and Clmp; then, it elevates the rate of survival of the parasite in mouse [204]. Overall, various studies highlighted the issue that the ability of host cellular miRNA networks as a tool may control xeno-infection dissemination. The host's miRNAs as immunomodulatory agents may target some pathogenic factors. On the other hand, because of the conserved properties of miRNAs in different organisms, some parasite-derived miRNAs may target the host's transcripts. Therefore, there are reciprocally associations between host miRNAs and related infectious agents.

\section{Future perspective}

Given the aforementioned contents on miRNA properties, the precise studies of isomiR profiling, arm selection, and arm switching can be applied to the related diseases that need reasonable and advantageous methods for their specific detection to be used as prognostic and diagnostic markers. Besides, the impressive variants of miRNAs are significant in miRNAs-targeted therapy. Ideal characteristics of miRNA and their related isomiRs, as well as their dependency on individual characteristics such as population origin, race, a person's sex, and on tissue state/type, will provide an improvement in comprehension of the molecular mechanisms of diseases. Also, it provides new insights into novel approaches to improve personalized medicine. However, it still needs further investigation [205-207]. Furthermore, owing to epigenetically controlling miRNAs in their processing and expression levels, epigenetic-controlling agents can be used for regulation of them. With regard to the relationship between IncRNA and miRNA, lncRNAs can be used to control spongerelated miRNAs as a therapeutic strategy that may be considered another way for regulating miRNAs in various diseases. Finally, considering the roles of miRNA in 
xeno-infectious diseases, it can be controlled with mentioned approaches to attenuate infections.

\section{Conclusion}

To highlight the role of miRNAs in the related diseases, some of them are collected in this review. Numerous studies have established that miRNAs are involved in both spectra of normal biological functions and diseases by directly or indirectly regulating multiple cellular transcripts by affecting epigenetic-related enzymes, thereby interfering with lncRNA functions with CeRNA roles. Also, they modulate xeno-infectious diseases by host and/or infection factors such as related transcripts and proteins, etc. On the other hand, complexities in the structure of their miRNAs such as isomiRs, arm selection, and arm switching can demonstrate the critical roles of miRNAs in the development of various diseases. Regarding the combination of structural properties of miRNAs and their interaction with epigenetics and other non-coding intracellular RNAs, they can also be affected by xeno-infectious agents such as viruses, parasites and bacteria, etc. Therefore, the potential role of miRNAs should be further considered because they are valuable prognostic and diagnostic biomarkers. In addition, to be applied as therapeutic agents, further studies are needed to be conducted from bench to bedside because miRNAs provide new insights into some mechanisms of complex diseases such as cancer, as well as neurodegenerative and xeno-infectious diseases that can be efficiently used in personalized medicine to control the diseases.

\footnotetext{
Abbreviations

Acsod3: Extracellular superoxide dismutase 3; ADR: RNA-specific adenosine deaminase; Ago: Argonaute protein; ARS: Arm switching; BoDV-1: Borna disease virus 1; BRD4: Bromo domain-containing protein 4; CASMIR: Comprehensive Approach to Sequence-oriented isomiR annotation; CCA: Cholangiocarcinoma; CLL: Chronic lymphocytic leukemia; CRC: Colorectal cancer; DENV: Dengue virus; DGCR8: DiGeorge syndrome critical region 8; DNMT: DNA methyltransferase; EMT: Epithelial-Mesenchymal Transition; ESCC: Esophageal squamous cell carcinoma; ES: Embryonic Stem; Evs: Extracellular vesicle; EV71: Enterovirus 71; FN1: Fibronectin 1; GBM: Glioblastoma; HBV: Hepatitis B virus; HBx: Hepatitis B virus X protein; HCV: Hepatitis C virus; HDAC4: Histone deacetylase 4; HP1a: Heterochromatin protein 1a; HSCs: Hepatic stellate cells; HSV-1: Herpes Simplex Virus-1; HTLV-1: Human T cell leukemia virus; HuR: Human antigen R, type 1; IAV: Influenza A virus; Lnc: Long Non-Coding; MBDs: Methyl-CpG-binding domains; MeCP2: Methyl-CpG-binding protein 2; miRNA: MicroRNA; MMP: Matrix metalloproteinase; m6A: N6-methyladenosine; m7G: N7-methylguanosine; NDV: Newcastle Disease Virus; OC: Ovarian cancer; pre-miRNA: Precursor miRNA; PACT: Protein activator of dsRNA-dependent protein kinase; RISC: RNA-induced silencing complex; SETDB1: SET domain bifurcated 1; SP1: Specificity protein 1; SRP14: Signal recognition particle 14; TCA: Tricarboxylic acid; TET: Ten-eleven translocation; TRBP: Trans-activating response RNA-binding protein; XPO5: Exportin-5; Xrn: 5'-3' Exoribonuclease; YWHAZ: Tyrosine3 monooxygenase/tryptophan5-monooxygenase activation protein zeta.
}

\section{Authors' contributions}

SH and MRA designed the study and drafted the manuscript. MR, FK was involved in data collection. FS critically revised the manuscript for important intellectual content. MRA supervised the study. All authors read and approved the final manuscript.

\section{Funding}

The study was supported by Immunology Research Center (Grant No: 60420) of Tabriz University of Medical sciences.

\section{Availability of data and materials}

Please contact the corresponding author for data requests.

\section{Ethics approval and consent to participate}

Not applicable.

\section{Consent for publication}

Not applicable.

\section{Competing interests}

The authors declare that they have no conflict of interest.

\section{Author details}

${ }^{1}$ Department of Medical Genetics, Faculty of Medicine, Tabriz University of Medical Sciences, Tabriz, Iran. ${ }^{2}$ Immunology Research Center, Tabriz University of Medical Sciences, Tabriz, Iran. ${ }^{3}$ Department of Biotechnology, Faculty of Science, University of Maragheh, Maragheh, Iran. ${ }^{4}$ Department of Immunology and Allergy, Academic Center for Education, Culture, and Research (ACECR), Tehran, Iran. ${ }^{5}$ Neuroscience Research Center, Iran University of Medical Sciences, Tehran, Iran.

Received: 27 May 2020 Accepted: 6 February 2021

Published online: 25 February 2021

\section{References}

1. Fateh A, Feizi MAH, Safaralizadeh R, Azarbarzin S. Importance of mir411-5p in colorectal cancer. J Biol Res Bollettino della Società Italiana di Biologia Sperimentale. 2018. https://doi.org/10.4081/jbr.2017.6511.

2. Kato M, Slack FJ. microRNAs: small molecules with big roles $C$ elegans to human cancer. Biol Cell. 2008;100(2):71-81.

3. Kaboli PJ, Rahmat A, Ismail P, Ling KH. MicroRNA-based therapy and breast cancer: a comprehensive review of novel therapeutic strategies from diagnosis to treatment. Pharmacol Res. 2015;97:104-21.

4. Kim Y-K, Kim B, Kim VN. Re-evaluation of the roles of DROSHA, exportin 5, and DICER in microRNA biogenesis. Proc Natl Acad Sci. 2016;113(13):E1881-9.

5. Wahid F, Shehzad A, Khan T, Kim YY. MicroRNAs: synthesis, mechanism, function, and recent clinical trials. Biochimica et Biophysica Acta (BBA)Mol Cell Res. 2010;1803(11):1231-43.

6. Swarts DC, Makarova K, Wang Y, Nakanishi K, Ketting RF, Koonin EV, et al. The evolutionary journey of Argonaute proteins. Biochimica et Biophysica Acta (BBA) Mol Cell Res. 2014;21(9):743.

7. Lv Q, Li Q, Zhang P, Jiang Y, Wang X, Wei Q, et al. Disorders of MicroRNAs in peripheral blood mononuclear cells: as novel biomarkers of ankylosing spondylitis and provocative therapeutic targets. BioMed Res Int. 2015;2015:1.

8. Ebert MS, Sharp PA. Roles for microRNAs in conferring robustness to biological processes. Cell. 2012;149(3):515-24.

9. Mitchelson KR, Qin W-Y. Roles of the canonical myomiRs miR-1,133 and-206 in cell development and disease. World J Biol Chem. 2015;6(3):162.

10. Xu X, Cai N, Zhi T, Bao Z, Wang D, Liu Y, et al. MicroRNA-1179 inhibits glioblastoma cell proliferation and cell cycle progression via directly targeting E2F transcription factor 5. Am J Cancer Res. 2017;7(8):1680.

11. Chen D, Sun Y, Yuan Y, Han Z, Zhang P, Zhang J, et al. miR-100 induces epithelial-mesenchymal transition but suppresses tumorigenesis, migration and invasion. PLoS Genet. 2014;10(2):e1004177. 
12. Van Huyen DJ-P, Tible M, Gay A, Guillemain R, Aubert O, Varnous S, et al. MicroRNAs as non-invasive biomarkers of heart transplant rejection. European Heart J. 2014;35(45):3194-202.

13. Yang G, Wu D, Zeng G, Jiang O, Yuan P, Huang S, et al. Correlation between miR-126 expression and DNA hypomethylation of CD4+ T cells in rheumatoid arthritis patients. Int J Clin Exp Pathol. 2015:8(8):8929.

14. Yang B, Lin H, Xiao J, Lu Y, Luo X, Li B, et al. The muscle-specific microRNA miR-1 regulates cardiac arrhythmogenic potential by targeting GJA1 and KCNJ2. Nat Med. 2007;13(4):486-91.

15. Li X. MiR-375, a microRNA related to diabetes. Gene. 2014;533(1):1-4.

16. Hanieh $\mathrm{H}$. Aryl hydrocarbon receptor-microRNA-212/132 axis in human breast cancer suppresses metastasis by targeting SOX4. Mol Cancer. 2015;14(1):1-13.

17. Sekar D, Islam VIH, Thirugnanasambantham K, Saravanan S. Relevance of miR-21 in HIV and non-HIV-related lymphomas. Tumor Biol. 2014;35(9):8387-93.

18. Vickers KC, Sethupathy P, Baran-Gale J, Remaley AT. Complexity of microRNA function and the role of isomiRs in lipid homeostasis. J Lipid Res. 2013;54(5):1182-91.

19. Wang $S, X u Y$, Li M, Tu J, Lu Z. Dysregulation of miRNA isoform level at $5^{\prime}$ end in Alzheimer's disease. Gene. 2016;584(2):167-72.

20. Zheng X, Carstens JL, Kim J, Scheible M, Kaye J, Sugimoto H, et al. Epithelial-to-mesenchymal transition is dispensable for metastasis but induces chemoresistance in pancreatic cancer. Nature. 2015;527(7579):525.

21. Ibuki Y, Nishiyama Y, Tsutani Y, Emi M, Hamai Y, Okada M, et al. Circulating microRNA/isomiRs as novel biomarkers of esophageal squamous cell carcinoma. PLoS ONE. 2020;15(4):e0231116.

22. Zhang Z, Pi J, Zou D, Wang $X, X u J$, Yu S, et al. microRNA arm-imbalance in part from complementary targets mediated decay promotes gastric cancer progression. Nat Commun. 2019;10(1):1-16.

23. Chen $L$, Sun $H$, Wang $C$, Yang $Y$, Zhang M, Wong G. miRNA arm switching identifies novel tumour biomarkers. EBioMedicine. 2018;38:37-46.

24. Bartel DP. MicroRNAs: genomics, biogenesis, mechanism, and function. Cell. 2004;116(2):281-97.

25. Guo L, Zhang $H$, Zhao $Y$, Yang $S$, Chen F. Selected isomiR expression profiles via arm switching? Gene. 2014:533(1):149-55.

26. Holubekova V, Mendelova A, Jasek K, Mersakova S, Zubor P, Lasabova Z. Epigenetic regulation by DNA methylation and miRNA molecules in cancer. Future Med. 2017;13:2217.

27. Monroig PDC, Calin GA. MicroRNA and epigenetics: diagnostic and therapeutic opportunities. Curr Pathobiol Rep. 2013;1(1):43-52.

28. Nie D, Fu J, Chen H, Cheng J, Fu J. Roles of microRNA-34a in epithelial to mesenchymal transition, competing endogenous RNA sponging and its therapeutic potential. Int J Mol Sci. 2019;20(4):861.

29. Behrouzi A, Alimohammadi M, Nafari AH, Yousefi MH, Rad FR, Vaziri F, et al. The role of host miRNAs on Mycobacterium tuberculosis. ExRNA. 2019;1(1):1-10.

30. Naqvi AR, Shango J, Seal A, Shukla D, Nares S. Herpesviruses and MicroRNAs: new pathogenesis factors in oral infection and disease? Front Immunol. 2018;9:2099.

31. Samir M Vaas LA Pessler F MicroRNAs in the host response to vira infections of veterinary importance. Front Veterinary Sci. 2016;3:86.

32. Han J, Lee Y, Yeom K-H, Kim Y-K, Jin H, Kim VNJG, et al. The DroshaDGCR8 complex in primary microRNA processing. Genes Dev. 2004;18(24):3016-27.

33. Zhao H, Gao A, Zhang Z, Tian R, Luo A, Li M, et al. Genetic analysis and preliminary function study of miR-423 in breast cancer. Tumor Biol. 2015:36(6):4763-71

34. Friedman RC, Farh KK-H, Burge CB, Bartel DP. Most mammalian mRNAs are conserved targets of microRNAs. Genome Res. 2009:19(1):92-105.

35. Bartel DP. MicroRNAs: target recognition and regulatory functions. Cell. 2009;136(2):215-33

36. Kozomara A, Birgaoanu M, Griffiths-Jones SJ. miRBase: from microRNA sequences to function. Nucleic Acid Res. 2019:47(D1):D155-62.

37. Fromm B, Keller A, Yang X, Friedlander MR, Peterson KJ, Griffiths-Jones SJ. Quo vadis microRNAs? Trends Genetics. 2020:36:461.

38. Backes C, Fehlmann T, Kern F, Kehl T, Lenhof H-P, Meese E, et al. miRCarta: a central repository for collecting miRNA candidates. Nucleic Acids Res. 2018:46(D1):D160-7.
39. Berezikov E. Evolution of microRNA diversity and regulation in animals. Nat Rev Genet. 2011;12(12):846.

40. Guo L, Chen F. A challenge for miRNA: multiple isomiRs in miRNAomics. Gene. 2014;544(1):1-7.

41. Neilsen CT, Goodall GJ, Bracken CP. IsomiRs-the overlooked repertoire in the dynamic microRNAome. Trends Genet. 2012;28(11):544-9.

42. Tan GC, Dibb N. IsomiRs have functional importance. Malays J Pathol. 2015;37(2):73-81

43. Muller H, Marzi MJ, Nicassio F. IsomiRage: from functional classification to differential expression of miRNA isoforms. Front Bioeng Biotechnol. 2014;2:38.

44. Plé H, Landry P, Benham A, Coarfa C, Gunaratne PH, Provost P. The repertoire and features of human platelet microRNAs. PLOS ONE. 2012;7(12):e50746.

45. Baran-Gale J, Fannin EE, Kurtz CL, Sethupathy P. Beta cell 5'-shifted isomiRs are candidate regulatory hubs in type 2 diabetes. PLoS ONE. 2013;8(9):e73240.

46. Ma H, Wu Y, Niu Q, Zhang J, Jia G, Manjunath N, et al. A sliding-bulge structure at the Dicer processing site of pre-miRNAs regulates alternative Dicer processing to generate 5'-isomiRs. Heliyon. 2016;2(9):e00148.

47. Wyman SK, Knouf EC, Parkin RK, Fritz BR, Lin DW, Dennis LM, et al. Posttranscriptional generation of miRNA variants by multiple nucleotidyl transferases contributes to miRNA transcriptome complexity. Genome Res. 2011;21(9):1450-61.

48. Burroughs AM, Ando Y, de Hoon MJ, Tomaru Y, Nishibu T, Ukekawa R, et al. A comprehensive survey of $3^{\prime}$ animal miRNA modification events and a possible role for $3^{\prime}$ adenylation in modulating miRNA targeting effectiveness. Genome Res. 2010;20(10):1398-410.

49. Burroughs AM, Ando Y, de Hoon ML, Tomaru Y, Suzuki H, Hayashizaki $Y$, et al. Deep-sequencing of human Argonaute-associated small RNAs provides insight into miRNA sorting and reveals Argonaute association with RNA fragments of diverse origin. RNA Biol. 2011;8(1):158-77.

50. Liu N, Abe M, Sabin LR, Hendriks G-J, Naqvi AS, Yu Z, et al. The exoribonuclease Nibbler controls $3^{\prime}$ end processing of microRNAs in Drosophila. Curr Biol. 2011:21(22):1888-93.

51. van der Kwast RV, Woudenberg T, Quax PH, Nossent AY. MicroRNA-411 and Its 5'-IsomiR have distinct targets and functions and are differentially regulated in the vasculature under ischemia. Mol Ther. 2020;28(1):157-70.

52. Tan GC, Chan E, Molnar A, Sarkar R, Alexieva D, Isa IM, et al. $5^{\prime}$ isomiR variation is of functional and evolutionary importance. Nucleic Acids Res. 2014:42(14):9424-35.

53. Loher P, Londin ER, Rigoutsos I. IsomiR expression profiles in human lymphoblastoid cell lines exhibit population and gender dependencies. Oncotarget. 2014;5(18):8790.

54. Magee RG, Telonis AG, Loher P, Londin E, Rigoutsos I. Profiles of miRNA isoforms and tRNA fragments in prostate cancer. Sci Rep. 2018;8(1):5314

55. Bhardwaj A, Singh $\mathrm{H}$, Trinidad CM, Albarracin CT, Hunt KK, Bedrosian I. The isomiR-140-3p-regulated mevalonic acid pathway as a potential target for prevention of triple negative breast cancer. Breast Cancer Res. 2018;20(1):150

56. Di Agostino S, Valenti F, Sacconi A, Fontemaggi G, Pallocca M, Pulito C, et al. Long non-coding MIR205HG depletes Hsa-miR-590-3p leading to unrestrained proliferation in head and neck squamous cell carcinoma. Theranostics. 2018;8(7):1850.

57. Liu S-Y, Li X-Y, Chen W-Q, Hu H, Luo B, Shi Y-X, et al. Demethylation of the MIR145 promoter suppresses migration and invasion in breast cancer. Oncotarget. 2017;8(37):61731.

58. Bofill-De XR, Chen K, Chen S, Tesic N, Randjelovic D, Skundric N, et al. QuagmiR: A Cloud-based Application for IsomiR Big Data Analytics. 2018.

59. Wu CW, Evans JM, Huang S, Mahoney DW, Dukek BA, Taylor WR, et al. A Comprehensive Approach to Sequence-oriented IsomiR annotation (CASMIR): demonstration with IsomiR profiling in colorectal neoplasia. BMC genomic. 2018;19(1):401.

60. Cho S, Jang I, Jun Y, Yoon S, Ko M, Kwon Y, et al. MiRGator v3. 0: a microRNA portal for deep sequencing, expression profiling and mRNA targeting. Nucleic Acids Res. 2012;41(D1):D252-7. 
61. Dunin-Horkawicz S, Czerwoniec A, Gajda MJ, Feder M, Grosjean H, Bujnicki JM. MODOMICS: a database of RNA modification pathways. Nucleic Acids Res. 2006;34:D145-9.

62. Pantano L, Estivill X, Martí E. SeqBuster, a bioinformatic tool for the processing and analysis of small RNAs datasets, reveals ubiquitous miRNA modifications in human embryonic cells. Nucleic Acids Res. 2010;38(5):e34.

63. Sablok G, Milev I, Minkov G, Minkov I, Varotto C, Yahubyan G, et al. isomiRex: web-based identification of microRNAs, isomiR variations and differential expression using next-generation sequencing datasets. FEBS Lettt. 2013;587(16):2629-34.

64. Zhang Y, Xu B, Yang Y, Ban R, Zhang H, Jiang X, et al. CPSS: a computational platform for the analysis of small RNA deep sequencing data. Bioinformatics. 2012;28(14):1925-7.

65. Liao Z, Li D, Wang X, Li L, Zou QJCB. Cancer diagnosis through IsomiR expression with machine learning method. Bioinformatics. 2018;13(1):57-63.

66. Urgese G, Paciello G, Acquaviva A, Ficarra E. isomiR-SEA: an RNA-Seq analysis tool for miRNAs/isomiRs expression level profiling and miRNAmRNA interaction sites evaluation. BMC Bioinformatics. 2016;17(1):1-13.

67. Barturen G, Rueda A, Hamberg M, Alganza A, Lebron R, Kotsyfakis M, et al. sRNAbench: profiling of small RNAs and its sequence variants in single or multi-species high-throughput experiments. Methods Next Generation Sequencing. 2014;1(1):21-31.

68. Lu Y, Baras AS, Halushka MKJB. miRge 2.0: An updated tool to comprehensively analyze microRNA sequencing data. 2018:250779.

69. Desvignes T, Batzel P, Sydes J, Eames BF, Postlethwait JH. miRNA analysis with Prost reveals evolutionary conservation of organ-enriched expression and post-transcriptional modifications in three-spined stickleback and zebrafish. Sci Rep. 2019;9(1):1-15.

70. Guo L, Liang T. MicroRNAs and their variants in an RNA world: implications for complex interactions and diverse roles in an RNA regulatory network. Brief Bioinform. 2016;19(2):245-53.

71. Desvignes T, Loher P, Eilbeck K, Ma J, Urgese G, Fromm B, et al. Unification of miRNA and isomiR research: the mirGFF3 format and the mirtop API. Bioinformatics. 2020;36(3):698-703.

72. Zhou H, Huang $X$, Cui H, Luo X, Tang Y, Chen S, et al. miR-155 and its star-form partner miR-155* cooperatively regulate type I interferon production by human plasmacytoid dendritic cells. Blood J Am Soc Hematol. 2010;116(26):5885-94.

73. Marco A, MacPherson Jl, Ronshaugen M, Griffiths-Jones S. MicroRNAs from the same precursor have different targeting properties. Silence. 2012;3(1):8.

74. Li S-C, Liao Y-L, Ho M-R, Tsai K-W, Lai C-H, Lin W-c, editors. miRNA arm selection and isomiR distribution in gastric cancer. BMC genomics; 2012: BioMed Central.

75. Gu S, Jin L, Zhang F, Huang Y, Grimm D, Rossi JJ, et al. Thermodynamic stability of small hairpin RNAs highly influences the loading process of different mammalian Argonautes. Proc Natl Acad Sci. 2011;108(22):9208-13.

76. Kwak PB, Tomari Y. The N domain of Argonaute drives duplex unwinding during RISC assembly. Nat Struct Mol Biol. 2012;19(2):145.

77. Xie M, Li M, Vilborg A, Lee N, Shu M-D, Yartseva V, et al. Mammalian $5^{\prime}$-capped microRNA precursors that generate a single microRNA. Cell. 2013;155(7):1568-80.

78. Zhou H, Arcila ML, Li Z, Lee EJ, Henzler C, Liu J, et al. Deep annotation of mouse iso-miR and iso-moR variation. Nucleic Acids Res. 2012;40(13):5864-75.

79. Schwarz DS, Hutvágner G, Du T, Xu Z, Aronin N, Zamore PD. Asymmetry in the assembly of the RNAi enzyme complex. Cell. 2003;115(2):199-208.

80. Woods S, Charlton S, Cheung K, Hao Y, Soul J, Reynard LN, et al. microRNA-seq of cartilage reveals an over-abundance of miR-140-3p which contains functional isomiRs. bioRxiv. 2020

81. Hu HY, Yan Z, Xu Y, Hu H, Menzel C, Zhou YH, et al. Sequence features associated with microRNA strand selection in humans and flies. BMC Genomics. 2009;10(1):413.

82. Noland $\mathrm{CL}$, Doudna JA. Multiple sensors ensure guide strand selection in human RNAi pathways. RNA. 2013;19(5):639-48.
83. Chatterjee S, Fasler M, Büssing I, Großhans H. Target-mediated protection of endogenous microRNAs in C. elegans. Dev Cell. 2011:20(3):388-96.

84. Kang S-M, Choi J-W, Hong S-H, Lee H-J. Up-regulation of microRNA* strands by their target transcripts. Int J Mol Sci. 2013;14(7):13231-40.

85. Pinhal D, Bovolenta LA, Moxon S, Oliveira AC, Nachtigall PG, Acencio $\mathrm{ML}$, et al. Genome-wide microRNA screening in Nile tilapia reveals pervasive isomiRs' transcription, sex-biased arm switching and increasing complexity of expression throughout development. Sci Rep. 2018;8(1):1-18

86. Li S-C, Tsai K-W, Pan H-W, Jeng Y-M, Ho M-R, Li W-H, editors. MicroRNA 3'end nucleotide modification patterns and arm selection preference in liver tissues. BMC systems biology; 2012: BioMed Central.

87. Murphy $\mathrm{Cl}$. Dual and opposing regulation of MMP1 and MMP13 by both arms of miR-675 in human articular chondrocytes. Cell Physiol Biochem. 2019:53:172-85.

88. Griffiths-Jones S, Hui JH, Marco A, Ronshaugen M. MicroRNA evolution by arm switching. EMBO Rep. 2011;12(2):172-7.

89. Guo L, Yu J, Yu H, Zhao Y, Chen S, Xu C, et al. Evolutionary and expression analysis of miR-\#-5p and miR-\#-3p at the miRNAs/isomiRs levels. BioMed Res Int. 2015;201:1.

90. Chou N-H, Lo Y-H, Wang K-C, Kang C-H, Tsai C-Y, Tsai K-W. MiR-193a-5p and-3p play a distinct role in gastric cancer: miR-193a-3p suppresses gastric cancer cell growth by targeting ETS1 and CCND1. Anticancer Res. 2018:38(6):3309-18.

91. Li Z-Y, Yang L, Liu X-J, Wang X-Z, Pan Y-X, Luo J-M. The long noncoding RNA MEG3 and its target miR-147 regulate JAK/STAT pathway in advanced chronic myeloid leukemia. EBioMedicine. 2018;34:61-75.

92. Lin MH, Chen YZ, Lee MY, Weng KP, Chang HT, Yu SY, et al. Comprehensive identification of microRNA arm selection preference in lung cancer: miR-324-5p and-3p serve oncogenic functions in lung cancer. 2018;15(6):9818-26

93. Joyce BT, Zheng Y, Zhang Z, Liu L, Kocherginsky M, Murphy R, et al. miRNA-Processing gene methylation and cancer risk. Cancer Epidemiol Prevention Biomarkers. 2018:27(5):550-7.

94. Pronina I, Klimov E, Burdennyy A, Beresneva E, Fridman M, Ermilova V, et al. Methylation of the genes for the microRNAs miR-129-2 and miR9-1, changes in their expression, and activation of their potential target genes in clear cell renal cell carcinoma. Mol Biol. 2017;51(1):61-71.

95. Benetatos L. miR-29b: a new demethylator in multiple myeloma. Cell Cycle. 2013;12(24):3718-9.

96. Cheng J, Guo S, Chen S, Mastriano SJ, Liu C, D'Alessio AC, et al. An extensive network of TET2-targeting MicroRNAs regulates malignant hematopoiesis. Cell Rep. 2013:5(2):471-81.

97. Cui Y, Li T, Yang D, Li S, Le W. miR-29 regulates Tet1 expression and contributes to early differentiation of mouse ESCs. Oncotarget. 2016;7(40):64932

98. Fabbri M, Garzon R, Cimmino A, Liu Z, Zanesi N, Callegari E, et al. MicroRNA-29 family reverts aberrant methylation in lung cancer by targeting DNA methyltransferases $3 \mathrm{~A}$ and 3B. Proc Natl Acad Sci. 2007;104(40):15805-10.

99. Lin LL, Wang W, Hu Z, Wang LW, Chang J, Qian H. Negative feedback of miR-29 family TET1 involves in hepatocellular cancer. Med Oncol. 2014;31(12):291.

100. Robaina MC, Mazzoccoli L, Arruda VO, de Souza Reis FR, Apa AG, de Rezende LMM, et al. Deregulation of DNMT1, DNMT3B and miR-29s in Burkitt lymphoma suggests novel contribution for disease pathogenesis. Exp Mol Pathol. 2015:98(2):200-7.

101. Wong CM, Wei L, Law CT, Ho DW, Tsang FH, Au SL, et al. Up-regulation of histone methyltransferase SETDB1 by multiple mechanisms in hepatocellular carcinoma promotes cancer metastasis. Hepatology (Baltimore, MD). 2016;63(2):474-87.

102. Wang H, An X, Yu H, Zhang S, Tang B, Zhang X, et al. MiR-29b/TET1/ZEB2 signaling axis regulates metastatic properties and epithelial-mesenchymal transition in breast cancer cells. Oncotarget. 2017;8(60):102119.

103. Niu M, Gao D, Wen Q, Wei P, Pan S, Shuai C, et al. MiR-29c regulates the expression of miR-34c and miR-449a by targeting DNA methyltransferase $3 a$ and $3 b$ in nasopharyngeal carcinoma. BMC Cancer. 2016;16(1):218

104. Chiang CL, Goswami S, Frissora FW, Xie Z, Yan PS, Bundschuh R, et al. ROR1-targeted delivery of miR-29b induces cell cycle arrest 
and therapeutic benefit in vivo in a CLL mouse model. Blood. 2019;134(5):432-44.

105. Huang YH, Kuo HC, Yang YL, Wang FS. MicroRNA-29a is a key regulon that regulates BRD4 and mitigates liver fibrosis in mice by inhibiting hepatic stellate cell activation. Int J Med Sci. 2019;16(2):212-20.

106. Afgar A, Fard-Esfahani P, Mehrtash A, Azadmanesh K, Khodarahmi F, Ghadir M, et al. MiR-339 and especially miR-766 reactivate the expression of tumor suppressor genes in colorectal cancer cell lines through DNA methyltransferase 3B gene inhibition. Cancer Biol Ther. 2016;17(11):1126-38.

107. Roscigno G, Quintavalle C, Donnarumma E, Puoti I, Diaz-Lagares A, laboni M, et al. MiR-221 promotes stemness of breast cancer cells by targeting DNMT3b. Oncotarget. 2016;7(1):580-92.

108. Azizi M, Teimoori-Toolabi L, Arzanani MK, Azadmanesh K, Fard-Esfahan P, Zeinali S. MicroRNA-148b and microRNA-152 reactivate tumor suppressor genes through suppression of DNA methyltransferase-1 gene in pancreatic cancer cell lines. Cancer Biol Ther. 2014;15(4):419-27.

109. Takata A, Otsuka M, Yoshikawa T, Kishikawa T, Hikiba Y, Obi S, et al. MicroRNA-140 acts as a liver tumor suppressor by controlling NF-KB activity by directly targeting DNA methyltransferase 1 (Dnmt1) expression. Hepatology (Baltimore, MD). 2013;57(1):162-70.

110. Zhu S, Zhang X, Guan H, Huang F, Wu L, Hou D, et al. miR-140-5p regulates $T$ cell differentiation and attenuates experimental autoimmune encephalomyelitis by affecting CD4(+)T cell metabolism and DNA methylation. Int Immunopharmacol. 2019;75:105778.

111. Chen Y, Luo J, Tian R, Sun H, Zou S. miR-373 negatively regulates methyl-CpG-binding domain protein 2 (MBD2) in hilar cholangiocarcinoma. Dig Dis Sci. 2011;56(6):1693-701.

112. Yao ZH, Yao XL, Zhang Y, Zhang SF, Hu J. miR-132 down-regulates methyl CpG binding protein 2 (MeCP2) during cognitive dysfunction following chronic cerebral hypoperfusion. Curr Neurovasc Res. 2017;14(4):385-96.

113. Zhao LY, Tong DD, Xue M, Ma HL, Liu SY, Yang J, et al. MeCP2, a target of miR-638, facilitates gastric cancer cell proliferation through activation of the MEK1/2-ERK1/2 signaling pathway by upregulating GIT1. Oncogenesis. 2017;6(7):e368.

114. Wada R, Akiyama Y, Hashimoto Y, Fukamachi H, Yuasa Y. miR-212 is downregulated and suppresses methyl-CpG-binding protein MeCP2 in human gastric cancer. Int J Cancer. 2010;127(5):1106-14.

115. Pan ZX, Zhang XY, Chen SR, Li CZ. Upregulated exosomal miR-221/222 promotes cervical cancer via repressing methyl-CpG-binding domain protein 2. Eur Rev Med Pharmacol Sci. 2019;23(9):3645-53.

116. Zhang Y, Li J, Jia S, Wang Y, Kang Y, Zhang W. Down-regulation of IncRNA-ATB inhibits epithelial-mesenchymal transition of breast cancer cells by increasing miR-141-3p expression. Biochem Cell Biol. 2018;97(2):193-200

117. Chen Y, Shin BC, Thamotharan S, Devaskar SU. Differential methylation of the micro-RNA $7 \mathrm{~b}$ gene targets postnatal maturation of murine neuronal Mecp2 gene expression. Dev Neurobiol. 2014;74(4):407-25.

118. Su M, Hong J, Zhao Y, Liu S, Xue X. MeCP2 controls hippocampal brain-derived neurotrophic factor expression via homeostatic interactions with microRNA132 in rats with depression. Mol Med Rep. 2015;12(4):5399-406.

119. Han K, Gennarino VA, Lee Y, Pang K, Hashimoto-Torii K, Choufani S, et al. Human-specific regulation of MeCP2 levels in fetal brains by microRNA miR-483-5p. Genes Dev. 2013;27(5):485-90.

120. Zhang Y, Chen M, Qiu Z, Hu K, McGee W, Chen X, et al. MiR-130a regulates neurite outgrowth and dendritic spine density by targeting MeCP2. Protein Cell. 2016;7(7):489-500.

121. Zhao H, Wen G, Huang Y, Yu X, Chen Q, Afzal TA, et al. MicroRNA-22 regulates smooth muscle cell differentiation from stem cells by targeting methyl CpG-binding protein 2. Arterioscler Thromb Vasc Biol. 2015;35(4):918-29.

122. Zhu F, Wu Q, Ni Z, Lei C, LiT, Shi Y. miR-19a/b and MeCP2 repress reciprocally to regulate multidrug resistance in gastric cancer cells. Int J Mol Med. 2018:42(1):228-36.

123. Yan B, Hu Z, Yao W, Le Q, Xu B, Liu X, et al. MiR-218 targets MeCP2 and inhibits heroin seeking behavior. Sci Rep. 2017;7:40413.

124. Bijkerk R, Trimpert C, van Solingen C, De Bruin RG, Florijn BW, Kooijman $\mathrm{S}$, et al. MicroRNA-132 controls water homeostasis through regulating
MECP2-mediated vasopressin synthesis. Am J Physiol Renal Physiol. 2018;315(4):F1129-38.

125. Yuan K, Xie K, Fox J, Zeng H, Gao H, Huang C, et al. Decreased levels of miR-224 and the passenger strand of miR-221 increase MBD2, suppressing maspin and promoting colorectal tumor growth and metastasis in mice. Gastroenterology. 2013;145(4):853-64.e9.

126. Liu C, Teng ZQ, McQuate AL, Jobe EM, Christ CC, von Hoyningen-Huene $\mathrm{SJ}$, et al. An epigenetic feedback regulatory loop involving microRNA-195 and MBD1 governs neural stem cell differentiation. PLoS ONE. 2013;8(1):e51436.

127. Du Y, XuY, Ding $L, Y a o H, Y u H$, Zhou T, et al. Down-regulation of miR141 in gastric cancer and its involvement in cell growth. J Gastroenterol. 2009;44(6):556-61.

128. Hur K, Toiyama Y, Takahashi M, Balaguer F, Nagasaka T, Koike J, et al. MicroRNA-200c modulates epithelial-to-mesenchymal transition (EMT) in human colorectal cancer metastasis. Gut. 2013;62(9):1315-26.

129. Korpal M, Kang Y. The emerging role of miR-200 family of microRNAs in epithelial-mesenchymal transition and cancer metastasis. RNA Biol. 2008;5(3):115-9.

130. Valladares-Ayerbes M, Reboredo M, Medina-Villaamil V, Iglesias-Díaz P, Lorenzo-Patiño MJ, Haz M, et al. Circulating miR-200c as a diagnostic and prognostic biomarker for gastric cancer. J Transl Med. 2012;10(1):186

131. Vrba L, Jensen TJ, Garbe JC, Heimark RL, Cress AE, Dickinson S, et al. Role for DNA methylation in the regulation of miR-200c and miR-141 expression in normal and cancer cells. PLoS ONE. 2010;5(1):e8697.

132. Lynch SM, O'Neill KM, McKenna MM, Walsh CP, McKenna DJ. Regulation of miR-200c and miR-141 by methylation in prostate cancer. Prostate. 2016;76(13):1146-59.

133. Neves R, Scheel C, Weinhold S, Honisch E, Iwaniuk KM, Trompeter H-I, et al. Role of DNA methylation in miR-200c/141 cluster silencing in invasive breast cancer cells. BMC Res Notes. 2010;3(1):219.

134. Zhou X, Wang Y, Shan B, Han J, Zhu H, Lv Y, et al. The downregulation of miR-200c/141 promotes ZEB1/2 expression and gastric cancer progression. Med Oncol. 2015;32(1):428.

135. Xin L, Liu L, Liu C, Zhou LQ, Zhou Q, Yuan YW, et al. DNA-methylation-mediated silencing of miR-7-5p promotes gastric cancer stem cell invasion via increasing Smo and Hes1. J Cell Physiol. 2020;235(3):2643-54.

136. Rodriguez-Antolin C, Felquera-Selas L, Pernia O, Vera O, Esteban I, Losantos Garcia I, et al. miR-7 methylation as a biomarker to predict poor survival in early-stage non-small cell lung cancer patients. Cell Biosci. 2019;9:63.

137. Vázquez-Garza E. MicroRNA: biogenesis, functions and objetives identification. 2018.

138. Rahimi G, Jafari N, Khodabakhsh M, Shirzad Z, Dogaheh HP. Upregulation of microRNA processing enzymes Drosha and Dicer in gestational diabetes mellitus. Gynecol Endocrinol. 2015;31(2):156-9.

139. Joyce BT, Zheng Y, Zhang Z, Liu L, Kocherginsky M, Murphy R, et al. MicroRNA Processing Gene Methylation and Cancer Risk. Cancer Epidemiol Prevention Biomarkers. 2018;27:550.

140. Cheng T-L, Wang Z, Liao Q, Zhu Y, Zhou W-H, Xu W, et al. MeCP2 suppresses nuclear microRNA processing and dendritic growth by regulating the DGCR8/Drosha complex. Dev Cell. 2014;28(5):547-60.

141. Stathopoulou A, Chhetri JB, Ambrose JC, Esteve P-O, Ji L, Erdjument-Bromage $\mathrm{H}$, et al. A novel requirement for DROSHA in maintenance of mammalian CG methylation. Nucleic Acids Res. 2017:45(16):9398-412.

142. Leaderer D, Hoffman AE, Zheng T, Fu A, Weidhaas J, Paranjape T, et al. Genetic and epigenetic association studies suggest a role of microRNA biogenesis gene exportin-5 (XPO5) in breast tumorigenesis. Int J Mol Epidemiol Genetics. 2011;2(1):9.

143. Cheng W, Qi Y, Tian L, Wang B, Huang W, Chen Y. Dicer promotes tumorigenesis by translocating to nucleus to promote SFRP1 promoter methylation in cholangiocarcinoma cells. Cell Death Dis. 2017;8(2):e2628.

144. Nesterova TB, Popova BC, Cobb BS, Norton S, Senner CE, Tang YA, et al. Dicer regulates Xist promoter methylation in ES cells indirectly through transcriptional control of Dnmt3a. Epigenetics Chromatin. 2008;1 (1):2.

145. Ting AH, Suzuki H, Cope L, Schuebel KE, Lee BH, Toyota M, et al. A requirement for DICER to maintain full promoter $\mathrm{CpG}$ island hypermethylation in human cancer cells. Can Res. 2008;68(8):2570-5. 
146. Zhu H, Gan X, Jiang X, Diao S, Wu H, Hu J. ALKBH5 inhibited autophagy of epithelial ovarian cancer through miR-7 and BCL-2. J Exp Clin Cancer Res. 2019:38(1):163.

147. Liu S, Zhuo L, Wang J, Zhang Q, Li Q, Li G, et al. METTL3 plays multiple functions in biological processes. American Journal of Cancer Research. 2020;10(6):1631

148. Xhemalce B, Robson SC, Kouzarides T. Human RNA methyltransferase BCDIN3D regulates microRNA processing. Cell. 2012;151(2):278-88.

149. Zhang R, Hao S, Yang L, Xie J, Chen S, Gu G. LINC00339 promotes cell proliferation and metastasis in pancreatic cancer via miR-497-5p/IGF1R axis. J BU Oncol. 2019;24(2):729-38.

150. Pandolfini L, Barbieri I, Bannister AJ, Hendrick A, Andrews B, Webster N, et al. METTL1 promotes let-7 MicroRNA processing via m7G methylation. Mol Cell. 2019;74(6):1278-90.e9.

151. Maia BM, Rocha RM, Calin GA. Clinical significance of the interaction between non-coding RNAs and the epigenetics machinery: challenges and opportunities in oncology. Epigenetics. 2014;9(1):75-80.

152. Huang C, Yang Y, Liu L. Interaction of long noncoding RNAs and microRNAs in the pathogenesis of idiopathic pulmonary fibrosis. Physiol Genomics. 2015:47(10):463-9.

153. Huang Z-A, Huang Y-A, You Z-H, Zhu Z, Yu C-Q, Huang W, et al. Predicting IncRNA-miRNA interaction via graph convolution auto-encoder. Front Genetics. 2019;10:758

154. Jia W, Chen W, Kang J. The functions of microRNAs and long non-coding RNAs in embryonic and induced pluripotent stem cells. Genomics Proteomics Bioinformatics. 2013;11(5):275-83.

155. Liao YW, Ho BC, Chen MH, Yu SL. Host relieves Inc-IRAK3-3-sequestered miR-891b to attenuate apoptosis in Enterovirus 71 infection. Cell Microbiol. 2019; 21:e13043.

156. Yang H, Liu P, Zhang J, Peng X, Lu Z, Yu S, et al. Long noncoding RNA MIR31HG exhibits oncogenic property in pancreatic ductal adenocarcinoma and is negatively regulated by miR-193b. Oncogene. 2016;35(28):3647.

157. Salmena L, Poliseno L, Tay Y, Kats L, Pandolfi PP. A ceRNA hypothesis: the Rosetta Stone of a hidden RNA language? Cell. 2011; 146(3):353-8.

158. Denzler R, Agarwal V, Stefano J, Bartel DP, Stoffel M. Assessing the ceRNA hypothesis with quantitative measurements of miRNA and target abundance. Mol Cell. 2014;54(5):766-76.

159. Ma J, Xiao Y, Tian B, Chen S, Zhang B, Wu J, et al. Long noncoding RNA Inc-ABCA12-3 promotes cell migration, invasion, and proliferation by regulating fibronectin 1 in esophageal squamous cell carcinoma. J Cell Biochem. 2020;121(2):1374-87.

160. Wei H, Hu J, Pu J, Tang Q, Li W, Ma R, et al. Long noncoding RNA HAGLROS promotes cell proliferation, inhibits apoptosis and enhances autophagy via regulating miR-5095/ATG12 axis in hepatocellular carcinoma cells. Int Immunopharmacol. 2019;73:72-80.

161. Zhu Y, Ni T, Lin J, Zhang C, Zheng L, Luo M. Long non-coding RNA H19, a negative regulator of microRNA-148b-3p, participates in hypoxia stress in human hepatic sinusoidal endothelial cells via NOX4 and eNOS/NO signaling. Biochimie. 2019;163:128-36

162. Guan $Y X$, Zhang MZ, Chen XZ, Zhang Q, Liu SZ, Zhang YL. Lnc RNA SNHG20 participated in proliferation, invasion, and migration of breast cancer cells via miR-495. J Cell Biochem. 2018:119(10):7971-81.

163. Huang G, Wang M, Li X, Wu J, Chen S, Du N, et al. TUSC7 suppression of Notch activation through sponging MiR-146 recapitulated the asymmetric cell division in lung adenocarcinoma stem cells. Life Sci. 2019:232:116630.

164. Jiang Z, Jiang C, Fang J. Up-regulated Inc-SNHG1 contributes to osteosarcoma progression through sequestration of miR-577 and activation of WNT2B/Wnt/ $\beta$-catenin pathway. Biochem Biophys Res Commun. 2018;495(1):238-45

165. Liu G, Jiang Z, Qiao M, Wang F. Lnc-GIHCG promotes cell proliferation and migration in gastric cancer through miR-1281 adsorption. Mol Genetics Genomic Med. 2019;7(6):e711.

166. Liu Y, Zhou J, Wang S, Song Y, Zhou J, Ren F. Long non-coding RNA SNHG12 promotes proliferation and invasion of colorectal cancer cells by acting as a molecular sponge of microRNA-16. Exp Ther Med. 2019;18(2):1212-20.

167. Zhang H, Cai Y, Zheng L, Zhang Z, Lin X, Jiang N. Long noncoding RNA NEAT1 regulate papillary thyroid cancer progression by modulating miR-129-5p/KLK7 expression. J Cell Physiol. 2018;233(10):6638-48.
168. Zhang Y, Li J, Jia S, Wang Y, Kang Y, Zhang W. Down-regulation of IncRNA-ATB inhibits epithelial-mesenchymal transition of breast cancer cells by increasing miR-141-3p expression. Biochem Cell Biol. 2019;97(2):193-200.

169. Ding X-M, Zhao L-J, Qiao H-Y, Wu S-L, Wang X-H. Long non-coding RNA-p21 regulates MPP+-induced neuronal injury by targeting miR-625 and derepressing TRPM2 in SH-SY5Y cells. Chem Biol Interact. 2019;307:73-81.

170. Hu M, Han Y, Zhang Y, Zhou Y, Ye L. IncRNA TINCR sponges miR-214-5p to upregulate ROCK1 in hepatocellular carcinoma. BMC Med Genet. 2020;21(1):1-6

171. Liu H, Wang B, Zhang J, Zhang S, Wang Y, Zhang J, et al. A novel Inc-PCF promotes the proliferation of TGF- $\beta$ 1-activated epithelial cells by targeting miR-344a-5p to regulate map3k11 in pulmonary fibrosis. Cell Death Dis. 2017;8(10):e3137

172. Ma N, Li S, Zhang Q, Wang H, Qin H, Wang S. Long non-coding RNA GAS5 inhibits ovarian cancer cell proliferation via the control of microRNA-21 and SPRY2 expression. Exp Therapeutic Med. 2018;16(1):73-82.

173. Yang E, Xue L, Li Z, Yi T. Lnc-AL445665 1-4 may be involved in the development of multiple uterine leiomyoma through interacting with miR-146b-5p. BMC Cancer. 2019;19(1):709.

174. Wang Y, Zhang X, Wang Z, Hu Q, Wu J, Li Y, et al. LncRNA-p23154 promotes the invasion-metastasis potential of oral squamous cell carcinoma by regulating Glut1-mediated glycolysis. Cancer Lett. 2018:434:172-83.

175. Zhu D, Huang $X$, Liang F, Zhao L. LncRNA miR503HG interacts with miR-31-5p through multiple ways to regulate cancer cell invasion and migration in ovarian cancer. J Ovarian Res. 2020;13(1):1-7.

176. Song H, He P, Shao T, Li Y, Li J, Zhang Y. Long non-coding RNA XIST functions as an oncogene in human colorectal cancer by targeting miR-132-3p. J buon. 2017:22(3):696-703.

177. Cai T, Liu Y, Xiao J. Long noncoding RNA MALAT 1 knockdown reverses chemoresistance to temozolomide via promoting micro RNA-101 in glioblastoma. Cancer Med. 2018;7(4):1404-15.

178. Tao F, Tian X, Lu M, Zhang Z. A novel IncRNA, Lnc-OC1, promotes ovarian cancer cell proliferation and migration by sponging miR-34a and miR-34c. J Genetics Genomics. 2018;45(3):137-45.

179. Xiong W-C, Han N, Wu N, Zhao K-L, Han C, Wang H-X, et al. Interplay between long noncoding RNA ZEB1-AS1 and miR-101/ZEB1 axis regulates proliferation and migration of colorectal cancer cells. Am J Transl Res. 2018;10(2):605

180. Rotival M, Siddle KJ, Silvert M, Pothlichet J, Quach H, Quintana-Murci L. Population variation of miRNAs and isomiRs and their impact on human immunity to infection. bioRxiv. 2020.

181. Zheng Z, Ke X, Wang M, He S, Li Q, Zheng C, et al. Human microRNA hsa-miR-296-5p suppresses enterovirus 71 replication by targeting the viral genome. J Virol. 2013;JVl:02655-12.

182. Shwetha S, Sharma G, Raheja H, Goel A, Aggarwal R, Das S. Interaction of miR-125b-5 $p$ with human antigen $\mathrm{R}$ mRNA: mechanism of controlling HCV replication. Virus Res. 2018;258:1-8.

183. Bai XT, Nicot C. miR-28-3p is a cellular restriction factor that inhibits human T cell leukemia virus, type 1 (HTLV-1) replication and virus infection. J Biol Chem. 2015;290(9):5381-90.

184. Chen C, Wu M, Zhang W, Lu W, Zhang M, Zhang Z, et al. MicroRNA-939 restricts Hepatitis $B$ virus by targeting Jmjd3-mediated and C/EBPacoordinated chromatin remodeling. Sci Rep. 2016;6:35974.

185. Zhao G, Hou J, Xu G, Xiang A, Kang Y, Yan Y, et al. Cellular microRNA miR-10a-5p inhibits replication of porcine reproductive and respiratory syndrome virus by targeting the host factor signal recognition particle 14. J Gen Virol. 2017:98(4):624-32.

186. Chen Y, Liu W, Xu H, Liu J, Deng Y, Cheng H, et al. MicroRNA expression profiling in Newcastle disease virus-infected DF-1 cells by deep sequencing. Frontiers in microbiology. 2019;10.

187. Kobayashi K, Suemasa F, Sagara H, Nakamura S, Ino Y, Kobayashi K, et al. MiR-199a inhibits secondary envelopment of herpes simplex virus-1 through the downregulation of Cdc42-specific GTPase activating protein localized in golgi apparatus. Sci Rep. 2017;7(1):6650.

188. He J, Ji Y, Li A, Zhang Q, Song W, Li Y, et al. MiR-122 directly inhibits human papillomavirus E6 gene and enhances interferon signaling through blocking suppressor of cytokine signaling 1 in SiHa cells. PLoS ONE. 2014;9(9):e108410. 
189. Lanford RE, Hildebrandt-Eriksen ES, Petri A, Persson R, Lindow M, Munk $M E$, et al. Therapeutic silencing of microRNA-122 in primates with chronic hepatitis C virus infection. Science. 2010;327(5962):198-201.

190. Lee S, Song J, Kim S, Kim J, Hong Y, Kim Y, et al. Selective degradation of host MicroRNAs by an intergenic HCMV noncoding RNA accelerates virus production. Cell Host Microbe. 2013;13(6):678-90.

191. Khanizadeh S, Ravanshad M, Hosseini SY, Davoodian P, Almasian M, Khanlari Z. The effect of the hepatitis C virus (HCV) NS3 protein on the expression of miR-150, miR-199a, miR-335, miR-194 and miR-27a. Microb Pathog. 2017;110:688-93.

192. Feng G, Li J, Yang Z, Zhang S, Liu Y, Zhang W, et al. Hepatitis B virus $X$ protein promotes the development of liver fibrosis and hepatoma through downregulation of miR-30e targeting P4HA2 mRNA. Oncogene. 2017;36(50):6895-905.

193. Wu S, He L, Li Y, Wang T, Feng L, Jiang L, et al. miR-146a facilitates replication of dengue virus by dampening interferon induction by targeting TRAF6. J Infection. 2013;67(4):329-41.

194. Zhang R, Hao S, Yang L, Xie J, Chen S, Gu G. LINC00339 promotes cell proliferation and metastasis in pancreatic cancer via miR-497-5p/IGF1R axis. J BUON. 2019:24(2):729-38.

195. Bavagnoli L, Campanini G, Forte M, Ceccotti G, Percivalle E, Bione S, et al. Identification of a novel antiviral micro-RNA targeting the NS1 protein of the H1N1 pandemic human influenza virus and a corresponding viral escape mutation. Antiviral Res. 2019;2019:104593.

196. Guan W-J, Ni Z-Y, Hu Y, Liang W-H, Ou C-Q, He J-X, et al. Clinical characteristics of coronavirus disease 2019 in China. N Eng J Med. 2020;28:394.

197. Jernigan DB. Update: Public Health Response to the Coronavirus Disease 2019 Outbreak—United States, February 24, 2020. MMWR Morbidity and Mortality Weekly Report. 2020;69.

198. Gao W, Li L. Advances on presymptomatic or asymptomatic carrier transmission of COVID-19. Zhonghua liu xing bing xue za zhi Zhonghua liuxingbingxue zazhi. 2020;41:485.

199. Yuan C, Burns MB, Subramanian S, Blekhman R. Interaction between Host MicroRNAs and the gut microbiota in colorectal cancer. mSsystems. 2018. https://doi.org/10.1128/mSystems.00205-17.
200. Zhou X, Xu G, Yin C, Jin W, Zhang G. Down-regulation of miR-203 induced by Helicobacter pylori infection promotes the proliferation and invasion of gastric cancer by targeting CASK. Oncotarget. 2014;5(22):11631.

201. Yuan D, Luo S, Xu L, Zeng X, Wu Z. Regulatory effect of host miR$101 \mathrm{~b}-3 \mathrm{p}$ on parasitism of nematode Angiostrongylus cantonensis via superoxide dismutase 3. Biochim Biophys Acta. 2019;1862(5):557-66.

202. Cannella D, Brenier-Pinchart M-P, Braun L, Van Rooyen JM, Bougdour A, Bastien O, et al. miR-146a and miR-155 delineate a MicroRNA fingerprint associated with Toxoplasma persistence in the host brain. Cell reports. 2014;6(5):928-37.

203. Zeiner GM, Norman KL, Thomson JM, Hammond SM, Boothroyd JC. Toxoplasma gondii infection specifically increases the levels of key host microRNAs. PLoS ONE. 2010;5(1):e8742.

204. Liu J, Zhu L, Wang J, Qiu L, Chen Y, Davis RE, et al. Schistosoma japonicum extracellular vesicle miRNA cargo regulates host macrophage functions facilitating parasitism. PLoS Pathog. 2019;15(6):e1007817.

205. Tan W, Liu B, Qu S, Liang G, Luo W, Gong C. MicroRNAs and cancer: key paradigms in molecular therapy. Oncology letters. 2018;15(3):2735-42.

206. Telonis AG, Magee R, Loher P, Chervoneva I, Londin E, Rigoutsos I. Knowledge about the presence or absence of miRNA isoforms (isomiRs) can successfully discriminate amongst 32 TCGA cancer types. Nucleic Acids Res. 2017;45(6):2973-85.

207. Detassis S, Grasso M, Del Vescovo V, Denti MA. microRNAs make the call in cancer personalized medicine. Front Cell Deve Biol. 2017;5:86.

208. Peng CL, Zhao XJ, Wei CC, Wu JW. LncRNA HOTAIR promotes colon cancer development by down-regulating miRNA-34a. Eur Rev Med Pharmacol Sci. 2019 Jul 1;23(13):5752-61.

\section{Publisher's Note}

Springer Nature remains neutral with regard to jurisdictional claims in published maps and institutional affiliations.
Ready to submit your research? Choose BMC and benefit from:

- fast, convenient online submission

- thorough peer review by experienced researchers in your field

- rapid publication on acceptance

- support for research data, including large and complex data types

- gold Open Access which fosters wider collaboration and increased citations

- maximum visibility for your research: over $100 \mathrm{M}$ website views per year

At BMC, research is always in progress.

Learn more biomedcentral.com/submissions 